\title{
Connections between atmospheric sulphuric acid and new particle formation during QUEST III-IV campaigns in Heidelberg and Hyytiälä
}

\author{
I. Riipinen ${ }^{1}$, S.-L. Sihto ${ }^{1}$, M. Kulmala ${ }^{1}$, F. Arnold ${ }^{2}$, M. Dal Maso ${ }^{1}$, W. Birmili ${ }^{3}$, K. Saarnio ${ }^{4}$, K. Teinilä ${ }^{4}$, \\ V.-M. Kerminen ${ }^{4}$, A. Laksonen ${ }^{4,5}$, and K. E. J. Lehtinen ${ }^{6}$ \\ ${ }^{1}$ University of Helsinki, Department of Physical Sciences, P.O. Box 64, 00014 University of Helsinki, Finland \\ ${ }^{2}$ Max Planck Institute for Nuclear Physics (MPIK), Atmospheric Physics Division, P.O. Box 103980, 69029 Heidelberg, \\ Germany \\ ${ }^{3}$ Leibniz Institute for Tropospheric Research, Permoserstrasse 15, 04318 Leipzig, Germany \\ ${ }^{4}$ Finnish Meteorological Institute, Erik Palmenin Aukio 1, P.O. Box 503, 00101 Helsinki, Finland \\ ${ }^{5}$ University of Kuopio, Department of Applied Physics, P.O. Box 1627, 70211 Kuopio, Finland \\ ${ }^{6}$ Finnish Meteorological Institute and University of Kuopio, Department of Applied Physics, P.O. Box 1627, 70211 Kuopio, \\ Finland
}

Received: 9 October 2006 - Published in Atmos. Chem. Phys. Discuss.: 25 October 2006

Revised: 24 January 2007 - Accepted: 3 April 2007 - Published: 17 April 2007

\begin{abstract}
This study investigates the connections between atmospheric sulphuric acid and new particle formation during QUEST III and BACCI/QUEST IV campaigns. The campaigns have been conducted in Heidelberg (2004) and Hyytialä (2005), the first representing a polluted site surrounded by deciduous forest, and the second a rural site in a boreal forest environment. We have studied the role of sulphuric acid in particle formation and growth by determining 1) the power-law dependencies between sulphuric acid $\left(\left[\mathrm{H}_{2} \mathrm{SO}_{4}\right]\right)$, and particle concentrations $\left(N_{3-6}\right)$ or formation rates at $1 \mathrm{~nm}$ and $3 \mathrm{~nm}\left(J_{1}\right.$ and $\left.J_{3}\right) ; 2$ ) the time delays between $\left[\mathrm{H}_{2} \mathrm{SO}_{4}\right]$ and $N_{3-6}$ or $J_{3}$, and the growth rates for 1$3 \mathrm{~nm}$ particles; 3 ) the empirical nucleation coefficients $A$ and $K$ in relations $J_{1}=A\left[\mathrm{H}_{2} \mathrm{SO}_{4}\right]$ and $J_{1}=K\left[\mathrm{H}_{2} \mathrm{SO}_{4}\right]^{2}$, respectively; 4) theoretical predictions for $J_{1}$ and $J_{3}$ for the days when no significant particle formation is observed, based on the observed sulphuric acid concentrations and condensation sinks. In both environments, $N_{3-6}$ or $J_{3}$ and $\left[\mathrm{H}_{2} \mathrm{SO}_{4}\right]$ were linked via a power-law relation with exponents typically ranging from 1 to 2 . The result suggests that the cluster activation theory and kinetic nucleation have the potential to explain the observed particle formation. However, some differences between the sites existed: The nucleation coefficients were about an order of magnitude greater in Heidelberg than in Hyytiälä conditions. The time lags between $J_{3}$ and $\left[\mathrm{H}_{2} \mathrm{SO}_{4}\right]$ were consistently lower than the corresponding
\end{abstract}

Correspondence to: I. Riipinen

(ilona.riipinen@helsinki.fi) delays between $N_{3-6}$ and $\left[\mathrm{H}_{2} \mathrm{SO}_{4}\right]$. The exponents in the $J_{3} \propto\left[\mathrm{H}_{2} \mathrm{SO}_{4}\right]^{n_{J 3}}$-connection were consistently higher than or equal to the exponents in the relation $N_{3-6} \propto\left[\mathrm{H}_{2} \mathrm{SO}_{4}\right]^{n_{N 36}}$. In the $J_{1}$ values, no significant differences were found between the observed rates on particle formation event days and the predictions on non-event days. The $J_{3}$ values predicted by the cluster activation or kinetic nucleation hypotheses, on the other hand, were considerably lower on non-event days than the rates observed on particle formation event days. This study provides clear evidence implying that the main process limiting the observable particle formation is the competition between the growth of the freshly formed particles and their loss by scavenging, rather than the initial particle production by nucleation of sulphuric acid. In general, it can be concluded that the simple models based on sulphuric acid concentrations and particle formation by cluster activation or kinetic nucleation can predict the occurence of atmospheric particle formation and growth well, if the particle scavenging is accurately accounted for.

\section{Introduction}

The formation of new secondary atmospheric aerosol particles and their subsequent growth has been observed at various locations around the world (Kulmala et al., 2001a, 2004a). These particles can affect the climate in two distinct ways: first, by directly scattering the solar radiation

Published by Copernicus GmbH on behalf of the European Geosciences Union. 
and second, indirectly by acting as cloud condensation nuclei and therefore influencing the optical properties of clouds (Ramanathan et al., 2001; Lohmann and Feichter, 2005). On more local scales, the aerosol particles can affect the human health (e.g. Donaldson, 1998; Stieb et al., 2002) and deteriorate visibility (Cabada et al., 2004), particularly in polluted environments. To accurately quantify and model the regional and global effects of the formed particles, the mechanisms leading to their formation and growth need to be known.

Sulphuric acid has been identified as a key component in aerosol formation and growth (see e.g. Berndt et al., 2005; Korhonen et al., 1999; Kulmala, 2003; Kulmala et al., 2004b; Laakso et al., 2004a). The exact role of sulphuric acid, as well as the processes limiting the observed new particle formation, however, are still under discussion. Several studies such as Weber et al. (1995, 1997), Fiedler et al. (2005) and Sihto et al. (2006) report a close connection between measured atmospheric sulphuric acid and new particle formation at different locations.

Recently Kulmala et al. (2006) have proposed the activation of stable clusters (Kulmala et al., 2000) to be one of the possible mechanisms governing the observed atmospheric particle formation. The theory predicts a reservoir of stable clusters which are activated for growth at favourable conditions. In relation to this, Kulmala (2003) speculates that the limiting factor for the detected new particle formation and growth might not be the production of the initial particles but rather the competition between scavenging to the background particles and the particle growth to detectable sizes. The proposed activation processes involve sulphuric acid either as the activating vapour or as a constituent of the activated clusters. This theory is supported by the recent study by Sihto et al. (2006), which reports the cluster activation as a potential formation mechanism, along with kinetic nucleation (McMurry and Friedlander, 1979; Lushnikov and Kulmala, 1998). Spracklen et al. (2006) have implemented the cluster activation scheme as the particle formation mechanism in a global aerosol microphysics model. The model reproduces the observed secondary aerosol concentrations and the occurence of new particle formation with good accuracy.

In this paper we expand the work by Sihto et al. (2006), which studied the connections of new particle formation and sulphuric acid during the QUEST II campaign (March-April 2003) in Hyytiälä, Southern Finland. Sihto et al. (2006) observed that the nucleation mode particle concentration typically dependends on the sulphuric acid concentration via a power-law relation, the exponent being 1 or 2 . The proposed theory of atmospheric nucleation by cluster activation or kinetic nucleation could be used to explain the observed behaviour. Related to this, Sihto et al. (2006) investigated the strength of the coupling between the atmospheric nucleation rate and sulphuric acid concentrations by determining empirical nucleation coefficients based on the QUEST II data. In this work we do a similar analysis for the data collected during QUEST III and BACCI/QUEST IV campaigns in Hei- delberg (2004) and Hyytiälä (2005), in order to find out how broadly the results reported by Sihto et al. (2006) are valid. On one hand, we compare the conditions at the two different sites, Heidelberg representing a polluted environment surrounded by deciduous forest, and Hyytiälä a remote boreal forest site. On the other hand, the QUEST II and IV data allow for a comparison between two different springs in Hyytiälä: spring 2003 has the most particle formation event days so far, whereas the particle formation events in spring 2005 are much fewer in number. We study the dependence of the particle concentrations and formation rates on sulphuric acid with a computer-based fitting routine, and investigate the magnitude of the empirical nucleation coefficients in both locations and compare them to the results obtained by Sihto et al. (2006). We also study the days without new particle formation and investigate the relative importance of sulphuric acid concentrations and the condensation/coagulation sinks in the initial steps of particle formation and growth to detectable sizes, in order to find out the limiting factors for the observed new particle formation.

\section{Materials and methods}

\subsection{The utilised data sets}

In this work we used the data sets collected during the QUEST III and BACCI/QUEST IV campaigns. The QUEST III campaign has been carried out 28 February-3 April 2004 at the Max Plack Institute for Nuclear Physics in Heidelberg $\left(49^{\circ} 23^{\prime} \mathrm{N}, 08^{\circ} 41^{\prime} \mathrm{E}, 350 \mathrm{~m}\right.$ a.s.l. $)$, Germany, and the BACCI/QUEST IV campaign 5 April-16 May 2005 at the SMEAR II station in Hyytiälä $\left(61^{\circ} 51^{\prime} \mathrm{N}, 24^{\circ} 17^{\prime} \mathrm{E}\right.$, $181 \mathrm{~m}$ a.s.l.), Finland. The Heidelberg station is situated at a polluted site surrounded by deciduous forest (beech, maple, chestnut, birch, oak), whereas the SMEAR II station represents a typical rural site with extensive areas of Scots pine dominated forests surrounding it. For detailed descriptions of the measurement sites and the measurement equipment, see e.g. Fiedler et al. (2005), Hari and Kulmala (2005), Sihto et al. (2006), and http://www.atm.helsinki.fi/SMEAR/. The used data included particle size distributions measured with Twin-DMPS systems, sulphuric acid concentration measured with chemical ionization mass spectrometers (CIMS, see e.g. Hanke et al., 2002) and meteorological data, such as temperature and relative humidity. The time resolution was 10$15 \mathrm{~min}$ for the DMPS measurements and less than $1 \mathrm{~s}$ for the sulphuric acid data. In the analysis, however, the sulphuric acid data were averaged over $10-30 \mathrm{~min}$ time intervals to make it comparable with the particle concentration data. For comparison, we also utilised the data collected during the QUEST II campaign at the SMEAR II station in Hyytiälä (March-April 2003, see Sihto et al., 2006, for details).

In the case of BACCI/QUEST IV campaign in Hyytiälä, we also studied data on ammonia concentrations measured 
with a refluxing mist chamber. The device strips ammonia from the atmosphere and concentrates ammonium ions in the aqueous phase (Talbot et al., 1990). The sample flow in the system was $51 / \mathrm{min}$. Due to the low mass concentration of ammonia in the air, the sampling duration varied from 2 to $10 \mathrm{~h}$. The analysis of ammonium ions was conducted with a Dionex-500 ion chromatograph (Dionex, Sunnyvale, USA; columns CG12A + CS12A, electrochemical suppression CSRS, $20 \mathrm{mM}$ methanesulphonic acid eluent).

The data set collected at the Heidelberg station consisted of 38 days in total. According to the criteria presented by Dal Maso et al. (2005), clear new particle formation and growth was seen on 11 days (later often referred to as event days), whereas on 5 days, no indications of new particle formation were observed (non-event days). The rest of the days (22) were classified as "undefined" days. The Hyytiälä data set contained 22 days with new particle formation, 11 days with clearly no new particle formation, and 9 undefined days.

\subsection{Data analysis}

2.2.1 Connections between sulphuric acid, particle concentrations and formation rates

In order to investigate the connection between sulphuric acid concentrations and new particle formation and growth, we studied the correlations

$$
\begin{aligned}
& N_{3-6}\left(t+\Delta t_{N 36}\right) \propto\left[\mathrm{H}_{2} \mathrm{SO}_{4}\right]^{n_{N 36}}, \\
& J_{3}\left(t+\Delta t_{J 3}\right) \propto\left[\mathrm{H}_{2} \mathrm{SO}_{4}\right]^{n_{J 3}}, \\
& J_{1}(t) \propto\left[\mathrm{H}_{2} \mathrm{SO}_{4}\right]^{n_{J 1}},
\end{aligned}
$$

where $N_{3-6}$ refers to the 3-6 nm particle concentration (corresponding to the four lowest channels of the DMPS) and $J_{3}$ to the formation rate of the $3 \mathrm{~nm}$ particles. The time delays $\Delta t_{N 36}$ and $\Delta t_{J 3}$ are the intervals after which the effect of a change in the sulphuric acid concentration is shown in $3-6 \mathrm{~nm}$ particle concentration or formation rate. $J_{1}$ is the particle formation rate at $1 \mathrm{~nm}$, corresponding to the size region at which the atmospheric nucleation is assumed to take place. In particular, the values $n_{J 1}=1$ or $n_{J 1}=2$ in the correlation between $J_{1}$ and $\left[\mathrm{H}_{2} \mathrm{SO}_{4}\right]^{n_{J 1}}$ could imply the activation of pre-existing clusters $\left(n_{J 1}=1\right)$ or kinetic nucleation of sulphuric acid $\left(n_{J 1}=2\right)$ to be the dominating mechanisms for atmospheric new particle formation. In these cases the new particle formation rate (i.e. the atmospheric nucleation rate) can be simply written as

$J_{1}=A\left[\mathrm{H}_{2} \mathrm{SO}_{4}\right]$

or

$J_{1}=K\left[\mathrm{H}_{2} \mathrm{SO}_{4}\right]^{2}$,

where $A$ and $K$ are coefficients containing the details of the nucleation processes. According to our previous study ( $\mathrm{Si}$ hto et al., 2006) these nucleation mechanisms seem to be the best candidates for the atmospheric nucleation observed in Hyytiälä. Exponents larger than 2, on the other hand, could indicate that the atmospheric nucleation is thermodynamically limited (Kulmala et al., 2006): for instance, classical ternary nucleation theories predict the exponent to be well over 2 (see e.g. Napari et al., 2002 and Anttila et al., 2005). In our previous study we concentrated only on exponents and time delays related to sulphuric acid and $N_{3-6}$. In this work we expanded the analysis to the exponents and time delays related to sulphuric acid and particle formation rates, to be able to draw more sound conclusions on the nucleation mechanism and the processes governing the evolution of $N_{3-6}$ and $J_{3}$.

We studied the exponents and time delays relating the sulphuric acid and particle concentrations and formation rates, as well as the magnitude of the coefficients $A$ and $K$ at both measurement sites. We fitted the values for the exponents, time delays and nucleation coefficients for each new particle formation event day by maximizing the correlation coefficients for the relations presented in Eq. (1).

Assuming $\Delta t_{N 36}$ as the time that particles spend growing from 1 to $3 \mathrm{~nm}$, the growth rate from 1 to $3 \mathrm{~nm}$ can be expressed as

$G R_{1-3}=\frac{2 \mathrm{~nm}}{\Delta t_{N 36}}$.

We could thus estimate the 1-3 nm particle growth rates from the time delays obtained from the fits. Similar methods have been used by e.g. Weber et al. (1997); Fiedler et al. (2005) and Sihto et al. (2006).

We obtained the $N_{3-6}$ values directly from the measurement data, whereas $J_{3}$ and $J_{1}$ were calculated from the data as described below. The non-event and undefined days were also analysed in order to check the possible connection between $N_{3-6}$ and $\left[\mathrm{H}_{2} \mathrm{SO}_{4}\right]$, and to make a comparison between the days with and without clear new particle formation and growth.

\subsubsection{Particle formation rates at $3 \mathrm{~nm}\left(J_{3}\right)$ and $1 \mathrm{~nm}\left(J_{1}\right)$}

The time evolution of $N_{3-6}$ is described with a balance equation

$$
\frac{d N_{3-6}}{d t}=G R_{3} \cdot n_{3}-G R_{6} \cdot n_{6}-\mathrm{CoagS}_{3-6} \cdot N_{3-6},
$$

including terms for the growth into the $3-6 \mathrm{~nm}$ range over the $3 \mathrm{~nm}$ limit (the first term), out of the range over the $6 \mathrm{~nm}$ limit (the second term) and the loss by coagulation scavenging (the third term). The growth by intermodal coagulation is assumed to be negligible compared to condensation. Here, $G R_{6}$ denotes the particle growth rate at $6 \mathrm{~nm}$, and $n_{d}$ is a particle size distribution function, defined as $n_{d}=\mathrm{d} N_{d} / \mathrm{d} d p$, with $d_{p}=$ particle diameter. $\mathrm{CoagS}_{3-6}$ denotes the average coagulation sink for the 3-6 nm range (Kulmala et al., 2001b). By rearranging the terms, and denoting the first term on the 
right hand side of Eq. (5) by $J_{3}$, the following equation for the particle formation rate at $3 \mathrm{~nm}$ is obtained:

$J_{3}=\frac{d N_{3-6}}{d t}+\mathrm{CoagS}_{4} \cdot N_{3-6}+\frac{1}{3 \mathrm{~nm}} G R_{6} \cdot N_{3-6}$.

Here the coagulation loss for the interval $3-6 \mathrm{~nm}$ has been approximated by a term representing the loss of $4 \mathrm{~nm}$ sized particles, with hygroscopicity effects estimated as in Laakso et al. (2004b). The third term representing the condensation loss out of the size range $3-6 \mathrm{~nm}$ is obtained by approximating $n_{6}$ by $N_{3-6} /(6 \mathrm{~nm}-3 \mathrm{~nm})$. The $G R_{6}$ value used in the calculations was obtained from lognormal fits to DMPS data in the size range $3-7 \mathrm{~nm}$. If the fits were not available, the growth rate determined from $\Delta t_{N 36}(\mathrm{Eq} .4)$ was used.

When calculating the time derivative of $N_{3-6}$ from the measurement data by a simple approximation $\Delta N_{3-6} / \Delta t$, where the time interval $\Delta t=10 \mathrm{~min}$, the effect of noise results in big fluctuations in $J_{3}$ data. To filter out this noise, we applied a parabolic differentiation algorithm with a window size of 5 data points $(50 \mathrm{~min})$, which implies only a slight smoothing to ensure that we do not lose data significantly in the differentiation process. The differentiation algorithm significantly improved the quality of $J_{3}$-data, enabling us to distinguish peaks and other characteristics from the background level more reliably.

The atmospheric nucleation rate $J_{1}$ at time $t=t^{\prime}-\Delta t$ was estimated from the $J_{3}$ data using the method presented by Kerminen and Kulmala (2002):

$J_{1}(t)=J_{3}\left(t^{\prime}\right) \exp \left[\gamma \frac{C S^{\prime}}{G R_{1-3}}\left(\frac{1}{1 \mathrm{~nm}}-\frac{1}{3 \mathrm{~nm}}\right)\right]$.

Here $C S^{\prime}$ is the reduced condensation sink (in units $\mathrm{m}^{-2}$ ), $G R_{1-3}$ is the $1-3 \mathrm{~nm}$ growth rate (in $\mathrm{nm} / \mathrm{h}$ ) and $\gamma$ is a coefficient with a value of approximately $0.23 \mathrm{~m}^{2} \mathrm{~nm}^{2} \mathrm{~h}^{-1}$. The times $t$ and $t^{\prime}$ are related as $t=t^{\prime}-\Delta t$, where $\Delta t=2 \mathrm{~nm}$ $G R_{1-3}$. This equation was applied in a running window $[t$, $t+\Delta t]$ throughout each analysed day. For $G R_{1-3}$ and $t^{\prime}$ we utilized the fitted time delay between $N_{3-6}$ and the sulphuric acid data, and for the $C S^{\prime}$ the median value from the interval $[t, t+\Delta t]$. The formula can be applied also in the other direction to calculate $J_{3}$ from $J_{1}$.

\subsubsection{Fittings of the exponents and time delays}

In our previous study (Sihto et al., 2006) the exponents and time delays relating sulphuric acid concentration and nucleation mode particle concentrations were determined visually from the data. In this work we used a slightly more sophisticated method: we determined the values for the exponents $n_{N 36}$ and $n_{J 3}$, as well as the time delays $\Delta t_{N 36}$ and $\Delta t_{J 3}$ for each analysed day with a two-parameter fitting procedure, where the combination $(n, \Delta t)$ maximizing the correlation coefficient between $\left[\mathrm{H}_{2} \mathrm{SO}_{4}\right]$ and $N_{3-6}$ or $J_{3}$ was chosen. In the fittings, the exponent was varied in the steps of 0.01 and the time delay in $10 \mathrm{~min}$. intervals, corresponding to the time resolution of the particle measurements. In the case of $J_{1}$, no time delay with respect to $\left[\mathrm{H}_{2} \mathrm{SO}_{4}\right]$ was assumed and only the exponent $n_{J 1}$ was fitted, assuming it to have a discrete value 1,2 or 3 , consistently with the nucleation theories. An important advantage of this method compared to e.g. leastsquares fitting is that it gives more statistical weight to the temporal evolution of the data, rather than the magnitude of the correlated points: the correlation analysis gives the maximum correlation in the case where the shape of the curves is the most similar, whereas in the least squares fitting the absolute differences of the magnitudes of the compared curves are minimised. The correlation analysis is more suitable for our pourpose, as we want to find the exponents that best reproduce the shapes of the curves. However, we made a comparison with a least squares fit and in most of the studied cases, the results agreed well. We also re-analysed the data from the QUEST II campaign presented in our previous paper, to check the consistency of the two approaches, and the results obtained with the visual inspection are essentially the same as obtained with our fittings.

\subsubsection{Determining the nucleation coefficients $A$ and $K$}

In order to investigate the applicability of the proposed atmospheric nucleation schemes - particularly cluster activation and kinetic nucleation - we calculated the formation rate of $1 \mathrm{~nm}$ particles $\left(J_{1}\right)$ from the particle measurements (Eqs. 6 and 7). The obtained $J_{1}$ was compared with the $J_{1}$ calculated from the sulphuric acid data according to Eqs. (2) and (3). The nucleation coefficients $A$ and $K$ were kept as free parameters which were determined with least squares fits to the $J_{1}$ estimated from the particle measurements. To doublecheck the values of $A$ and $K$ we performed the fitting also to $J_{3}$-data: $J_{1}$ calculated from sulphuric acid was scaled to the formation rate of $3 \mathrm{~nm}$ particles using Eq. (7) in the opposite direction, and the obtained estimate for $J_{3}$ was compared with the $J_{3}$ calculated from the particle measurements.

\subsubsection{Analytical approach connecting the exponents $n_{N 36}$ and $n_{J 3}$}

The actual connections between $N_{3-6}, J_{3}$ and $J_{1}$ are complicated, and the relations between the exponents connecting them to the sulphuric acid are affected by, for instance, changes in the particle growth rates as well as the condensation and coagulation sinks (see Eqs. 6 and 7). To have a simple theoretical reference with which to compare the results obtained from the experimental data, we derived an analytical expression for $J_{3}$ that links the exponents $n_{N 36}$ and $n_{J 3}$. The detailed derivation of the expression is presented in Appendix A. Using the relation between $N_{3-6}$ and $\left[\mathrm{H}_{2} \mathrm{SO}_{4}\right]^{n_{N 36}}$ and assuming a simple sinusoidal production term for $\left[\mathrm{H}_{2} \mathrm{SO}_{4}\right]$ we obtained an expression for $J_{3}$ as a function of $\left[\mathrm{H}_{2} \mathrm{SO}_{4}\right]$ and $n_{N 36}$ : 

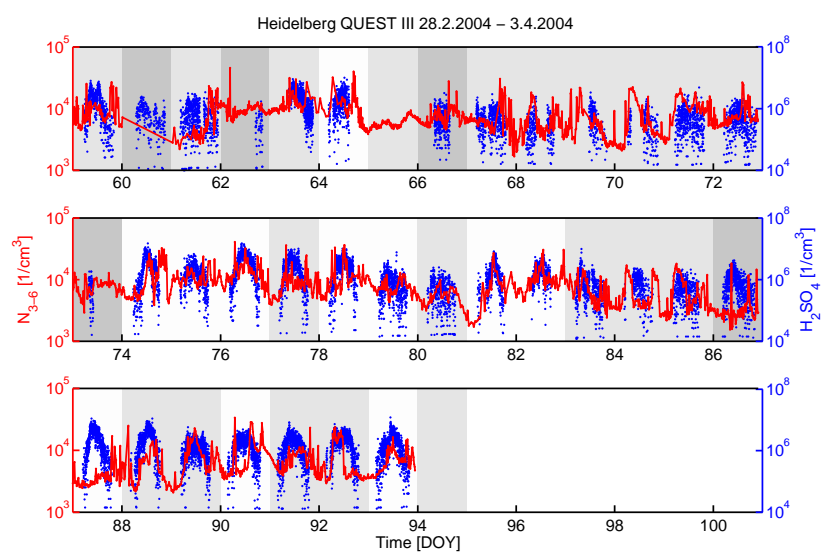

Fig. 1a. The particle number concentrations in the $3-6 \mathrm{~nm}$ size range (red) and sulphuric acid concentration (blue) measured during the QUEST III campaign in Heidelberg. The data is presented in two-week -periods. The particle formation event days are presented on white background. Non-event days are shaded with dark and undefined days with light gray.

$$
\begin{aligned}
J_{3}= & B \cdot\left[\mathrm{H}_{2} \mathrm{SO}_{4}\right]^{n_{N 36}-1}+ \\
& D \cdot\left[\mathrm{H}_{2} \mathrm{SO}_{4}\right]^{n_{N 36}}+E \cdot\left[\mathrm{H}_{2} \mathrm{SO}_{4}\right]^{n_{N 36}+1},
\end{aligned}
$$

where the coefficients $B, D$ and $E$ depend on e.g. CoagS $_{3-6}, C S$ (condensation sink), $G R_{1-3}$ and $n_{N 36}$ (see Appendix A for details). By comparing the magnitude of the terms in Eq. (8), we get a theoretical estimate for the dominating power of $\left[\mathrm{H}_{2} \mathrm{SO}_{4}\right]$ in the $J_{3}$ expression. We chose to use the $n_{N 36}$ as the reference (instead of $n_{J 3}$ ), since it can be directly and reliably determined from the measurement data. Even though desirable, linking the exponents $n_{J 3}$ and $n_{J 1}$ is considerably more difficult because of the exponential relation between $J_{1}$ and $J_{3}$, containing the $G R_{1-3}$ (which is presumably a function of $\left[\mathrm{H}_{2} \mathrm{SO}_{4}\right]$ ) in the exponential term (Eq. 7).

\section{Results and discussion}

3.1 Correlations of sulphuric acid and freshly nucleated particles

\subsubsection{Correlation of sulphuric acid and $N_{3-6}$ during new particle formation}

The exponents $n_{N 36}$ and the time delays $\Delta t_{N 36}$ were determined for all new particle formation days for which sulphuric acid data were available. In Heidelberg (QUEST III) this corresponded to 10 days, and in Hyytiälä (BACCI/QUEST IV) 18 days in total. Figure 1a shows the sulphuric acid and 3-6 nm particle concentrations for the QUEST III campaign, and Fig. $1 \mathrm{~b}$ shows the corresponding plot for the
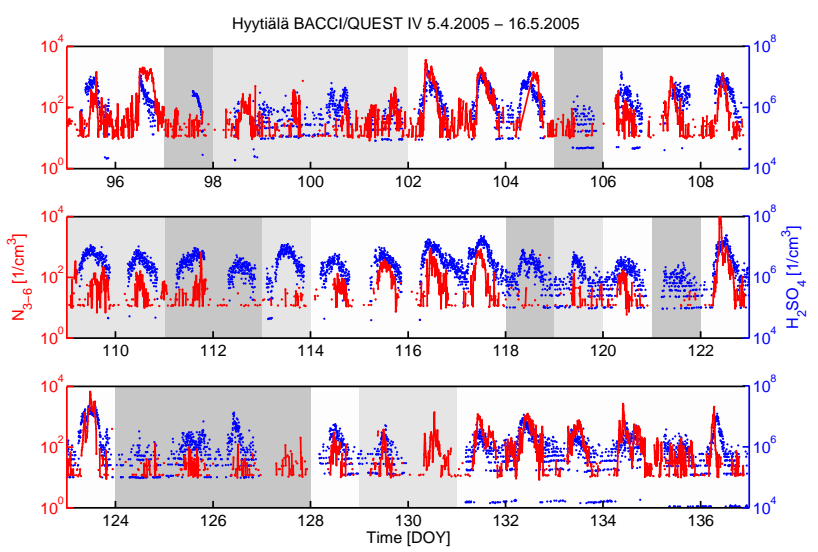

Fig. 1b. The particle number concentrations in the $3-6 \mathrm{~nm}$ size range (red) and sulphuric acid concentration (blue) measured during the BACCI/QUEST IV campaign in Hyytiälä. The data is presented in two-week -periods. The particle formation event days are presented on white background. Non-event days are shaded with dark and undefined days with light gray.

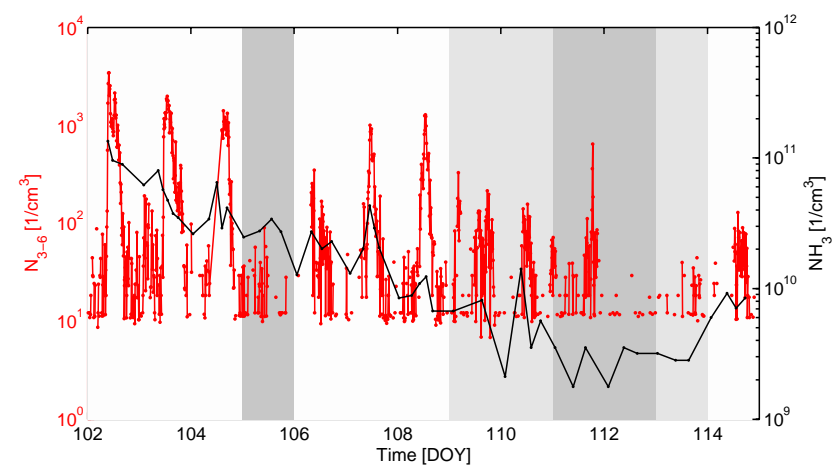

Fig. 1c. The particle number concentrations in the $3-6 \mathrm{~nm}$ size range (red) and the ammonia concentration (black) during the BACCI/QUEST IV campaign in Hyytiälä. The particle formation event days are presented on white background. Non-event days are shaded with dark and undefined days with light gray.

BACCI/QUEST IV. From these figures the clear correlation between $N_{3-6}$ and $\left[\mathrm{H}_{2} \mathrm{SO}_{4}\right]$ can be observed on particle formation event days (white background), whereas on the nonevent days (dark gray) this correlation seems to be absent. The latter applies also for most of the undefined days (light gray), particularly in Hyytiälä. In Heidelberg the undefined days resemble the event days with a clearer correlation between the particle concentrations and sulphuric acid. Generally, the correlation patterns are not as clear for the more polluted Heidelberg data as for Hyytiälä. In Fig. 1c we present the ammonia data available for the Hyytiälä campaign. No significant relation between the particle concentrations and ammonia is observed in Hyytiälä, meaning that the possible contribution of ammonia to the particle formation is not visible in this data set. 


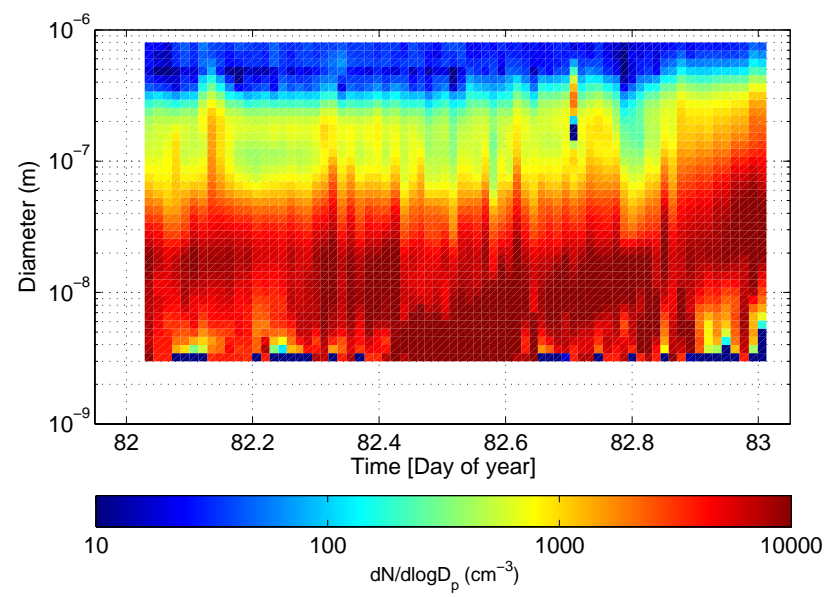

Fig. 2a. A surface plot of the particle size distribution data measured by a DMPS system 22 March 2003 (day 82) in Heidelberg. New particle formation and growth of the nucleation mode is observed during the day.

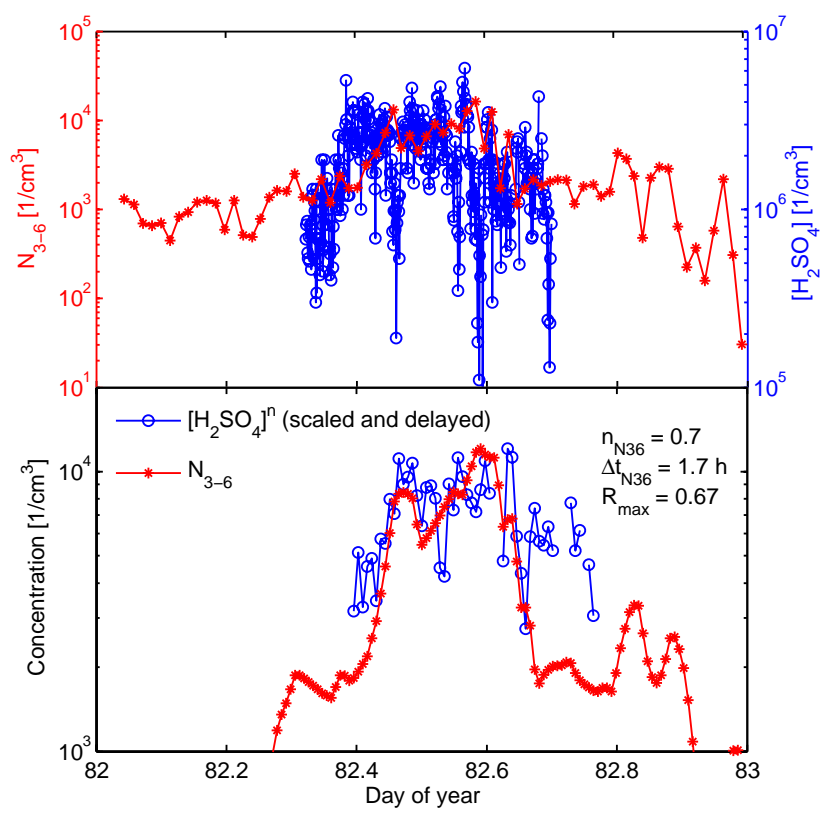

Fig. 2b. Upper panel: The number concentration of 3-6 nm particles (red curve) and the sulphuric acid concentration (blue curve) on 22 March 2004 in Heidelberg. Lower panel: The number concentration of 3-6 nm particles and the sulphuric acid concentration delayed with the fitted time lag $\left(\Delta \mathrm{t}_{N 36}=1.7 \mathrm{~h}\right)$ and raised to the fitted power $\left(n_{N 36}=0.7\right)$, corresponding to the maximum correlation $(R=0.67)$.

Figures 2a and 3a show typical new particle formation events observed in Heidelberg (22 March 2004) and Hyytiälä (27 April 2005), respectively. In both cases a clear new nucleation mode is formed around noon, and a continuous growth of the mode is seen during the day. As can be seen from the Figs. 1, 2 and 3, the background particle concentration and thus the condensation sink (see Kul-

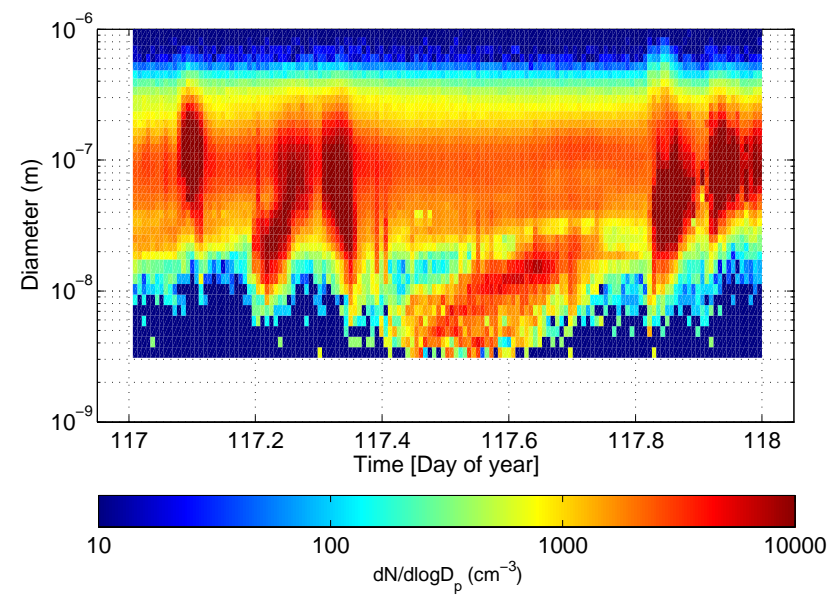

Fig. 3a. A surface plot of the particle size distribution data measured by a DMPS system 27 April 2005 (day 117) in Hyytiälä. New particle formation and growth of the nucleation mode is observed during the day.

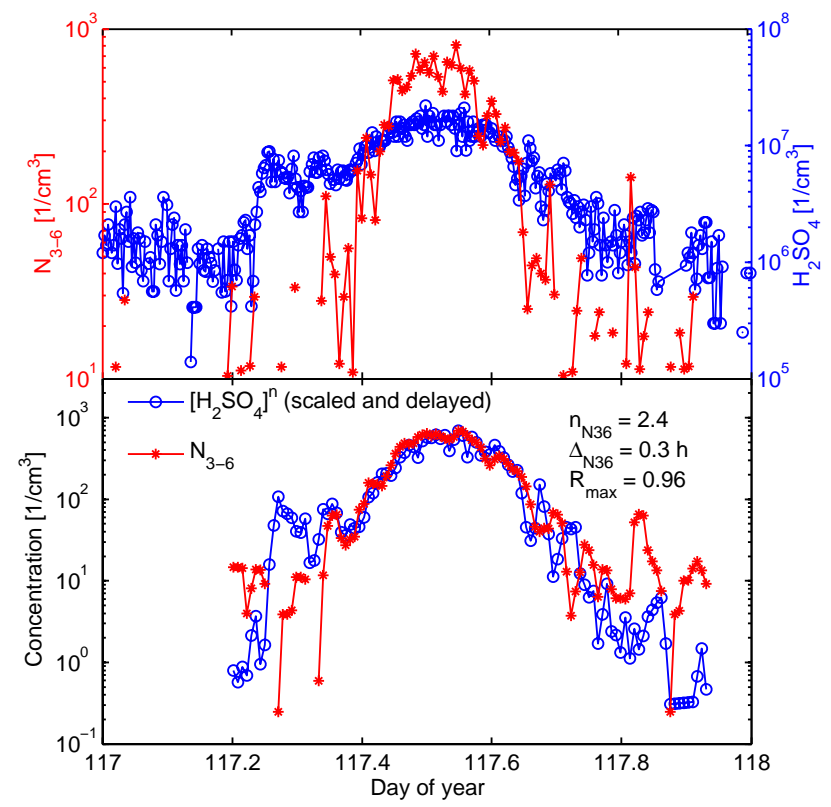

Fig. 3b. Upper panel: The number concentration of 3-6 nm particles (red curve) and the sulphuric acid concentration (blue curve) on 27 April 2005 in Hyytiälä. Lower panel: The number concentration of 3-6 nm particles (red curve) and the sulphuric acid concentration (blue curve) delayed with the fitted time lag $\left(\Delta t_{N 36}=0.3 \mathrm{~h}\right)$ and raised to the fitted power $\left(n_{N 36}=2.4\right)$, corresponding to the maximum correlation $(R=0.96)$.

mala et al., 2001b) in Heidelberg is typically significantly higher (mean $C S=1.4 \times 10^{-2} \mathrm{~s}^{-1}$ ) than in Hyytiälä (mean $\left.C S=4.2 \times 10^{-3} \mathrm{~s}^{-1}\right)$.

Figures $2 \mathrm{~b}$ and $3 \mathrm{~b}$ show exemplary plots of the diurnal variation of $N_{3-6}$ and sulphuric acid concentration (upper panel in both figures), and plots illustrating the $\left(n_{N 36}\right.$, $\Delta t_{N 36}$ )-fitting procedures (lower panel) for Heidelberg and 
Hyytiälä. On the exemplary day, the optimal fitting parameters for Heidelberg data were $n_{N 36}=0.7$ and $\Delta t_{N 36}=1.7 \mathrm{~h}$, the maximum correlation coefficient being 0.67 (see Fig. 2b). For Hyytiälä data (see Fig. 3b), the corresponding values were $n_{N 36}=2.4, \Delta t_{N 36}=0.3 \mathrm{~h}$ and $R_{\max }=0.96$.

Clear positive correlation between $N_{3-6}$ and sulphuric acid was observed during all new particle formation events at both locations. The mean value of the correlation coefficient between $N_{3-6}$ and sulphuric acid raised to the power $n_{N 36}$ is 0.75 ( $R$ in the range $0.57-0.90$ ) for Heidelberg, and 0.82 ( $R$ in the range $0.54-0.97)$ for Hyytiälä. Compared to the Hyytiälä conditions, the high and fluctuating background particle concentrations in Heidelberg made accurate correlation analysis often challenging. Also, in Heidelberg, the sulphuric acid data were available only from 08:00 a.m. to 06:00 p.m. for each day, which naturally affected the analysis as well.

In the fittings, the exponents $n_{N 36}$, were allowed to vary in the range $0.7-5$. Based on the fittings, the investigated days could be separated to four categories: days with $n_{N 36} \sim 1$, $n_{N 36} \sim 1.5, n_{N 36} \sim 2.0$ and days with $n_{N 36} \sim 2.5-3$. A more detailed division would not be appropriate, because in a much denser scale the differences in the correlation coefficients (i.e. in the quality of the fits) would be negligible. The distribution of the exponents for both measurement sites is summarized in Table 1. The exponents are similar to those found by Sihto et al. (2006) for the QUEST II campaign in Hyytiälä and Weber et al. $(1995,1997)$ at Mauna Loa and Idaho Hill.

A summary of the fitted time delays $\Delta t_{N 36}$ and the corresponding $1-3 \mathrm{~nm}$ growth rates is presented in Table 2 for Heidelberg and Hyytiälä, and the results from QUEST II are shown for comparison. In Heidelberg, the growth rates are in the range $0.9-2.7 \mathrm{~nm} / \mathrm{h}$, the mean and median values being $1.5 \mathrm{~nm} / \mathrm{h}$ and $1.3 \mathrm{~nm} / \mathrm{h}$. In Hyytiälä the growth rates are $0.6-10 \mathrm{~nm} / \mathrm{h}$, having their mean at $3.1 \mathrm{~nm} / \mathrm{h}$ and median at $1.1 \mathrm{~nm} / \mathrm{h}$. The day 123 in the BACCI/QUEST IV campaign was left out of the statistics as no clear time delay $\Delta t_{N 36}$ could be observed. The observations from Hyytiälä are similar first with the growth rates reported in our previous paper (mean $1.2 \mathrm{~nm} / \mathrm{h}$, median $1.2 \mathrm{~nm} / \mathrm{h}$, Sihto et al., 2006), and second with the $G R_{1-3}$ values determined from ion measurements by Hirsikko et al. (2005). The higher maximum growth rates during BACCI/QUEST IV $(10 \mathrm{~nm} / \mathrm{h})$ compared to QUEST II $(4.1 \mathrm{~nm} / \mathrm{h})$ could be explained by a more pronounced contribution of organics, as the QUEST IV took place later in spring. The $G R_{1-3}$ values obtained for the Heidelberg data set are significantly lower than those reported by Fiedler et al. (2005) (mean $G R_{1-3} 7.7 \mathrm{~nm} / \mathrm{h}$, median $6.3 \mathrm{~nm} / \mathrm{h}$ ). One reason for the large differences in the growth rates is the different analysis methods: Fiedler et al. (2005) determine $\Delta t_{N 36}$ by comparing $N_{3-6}$ and $\left[\mathrm{H}_{2} \mathrm{SO}_{4}\right]$ directly, whereas we take into account the possible power-law dependence of the two curves and fit the time delay numerically.

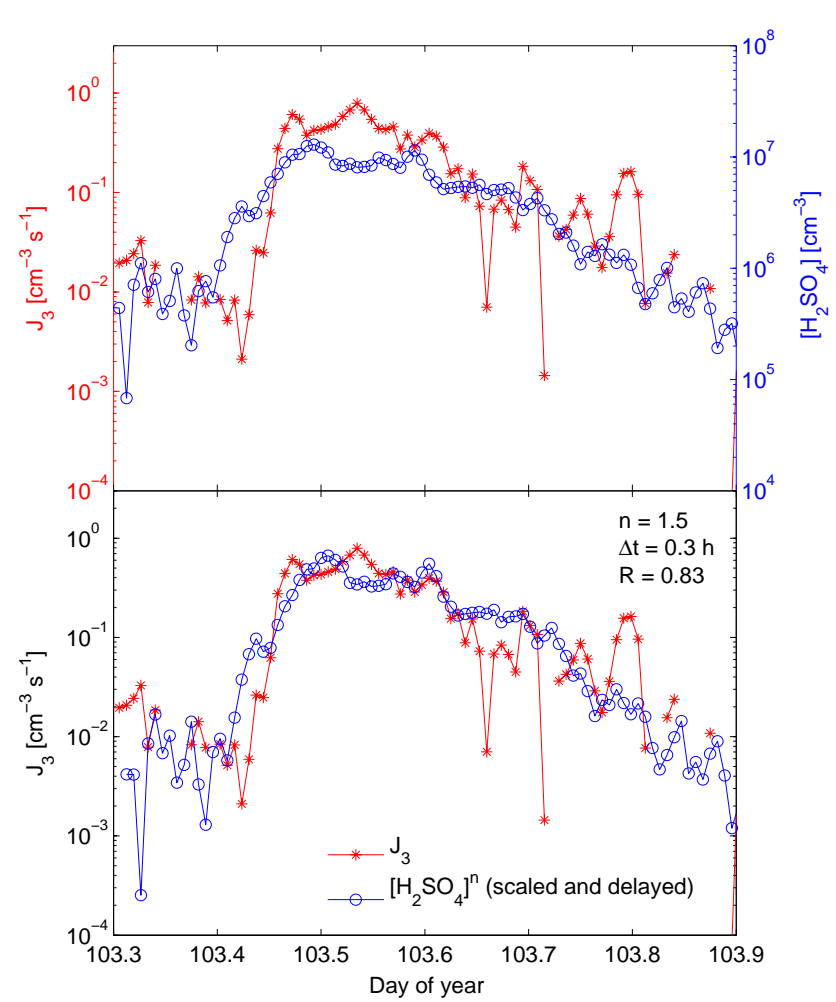

Fig. 4. A plot illustrating the fitting procedure for $J_{3}$ and $\left[\mathrm{H}_{2} \mathrm{SO}_{4}\right]$. Upper panel: The sulphuric acid concentration (blue curve) and the $3 \mathrm{~nm}$ particle formation rate (red curve) on 13 April 2005 in Hyytiälä. Lower panel: Fitting of sulphuric acid data to $J_{3}$ data, with sulphuric acid raised to the power $n_{J 3}=1.5$ and delayed by $\Delta t_{J 3}=0.3 \mathrm{~h}$. The correlation coefficient between the curves is $R=0.83$.

In the present study one value for $n_{N 36}$ as well as for $\Delta t_{N 36}$ was assumed to be valid throughout the day. This, however, might not be the case if the aerosol dynamic conditions, for instance the nucleation processes or the amount of condensable vapours, vary during the day.

3.1.2 Correlation of sulphuric acid and $J_{3}$ during new particle formation

On all the studied new particle formation days, the formation rate of $3 \mathrm{~nm}$ particles $\left(J_{3}\right)$ was observed to correlate with the sulphuric acid concentration. We performed a similar fitting procedure for the $J_{3}$ data as we did for the $N_{3-6}$, and searched the combination of the exponent $n_{J 3}$ and time delay $\Delta t_{J 3}$ that gave the maximum correlation coefficient for the relation $J_{3} \propto\left[\mathrm{H}_{2} \mathrm{SO}_{4}\left(t-\Delta t_{J 3}\right)\right]^{n_{J 3}}$. Figure 4 shows the fit to the $J_{3}$-data on 13 April 2005 in Hyytiälä, when the best agreement between the curves was obtained with an exponent $n_{J 3}=1.5$ and time delay $\Delta t_{J 3}=0.3 \mathrm{~h}$. The general agreement of the curves is satisfying.

The exponents $n_{J 3}$ typically varied between 1 and 3 in both locations. In Heidelberg, on 2 days (20\% of all analysed days) the exponent was approximately 1 , on $5(50 \%)$ 
Table 1 A classification of the particle formation event days during QUEST II-IV campaigns according to the exponent in the correlation $N_{3-6} \propto\left[\mathrm{H}_{2} \mathrm{SO}_{4}\right]^{n_{N 36}} . R$ refers to the correlation coefficient.

\begin{tabular}{lllll}
\hline & $\begin{array}{l}\text { Hyytiälä } \\
\text { QUEST II }\end{array}$ & $\begin{array}{l}\text { Heidelberg } \\
\text { QUEST III }\end{array}$ & $\begin{array}{l}\text { Hyytiälä } \\
\text { BACCI/QUEST IV }\end{array}$ & Total \\
\hline $\mathrm{n} \approx 1$ & $6(38 \%)$ & $6(60 \%)$ & $9(45 \%)$ & $21(46 \%)$ \\
$\mathrm{n} \approx 1.5$ & $4(25 \%)$ & $3(30 \%)$ & $2(10 \%$ & $9(20 \%)$ \\
$\mathrm{n} \approx 2$ & $5(31 \%)$ & $1(10 \%)$ & $6(30 \%)$ & $12(26 \%)$ \\
$\mathrm{n} \approx 2.5-3$ & $1(6 \%)$ & - & $3(15 \%)$ & $4(9 \%)$ \\
mean $R$ & 0.85 & 0.75 & 0.82 & \\
\hline
\end{tabular}

Table 2 The time delays and corresponding growth rates from 1 to $3 \mathrm{~nm}\left(G R_{1-3}\right)$ for the three QUEST campaigns.

\begin{tabular}{|c|c|c|c|c|c|c|}
\hline & \multicolumn{2}{|c|}{ Hyytiälä QUEST II } & \multicolumn{2}{|c|}{ Heidelberg QUEST III } & \multicolumn{2}{|c|}{ Hyytiälä BACCI/QUEST IV } \\
\hline & $\begin{array}{l}\Delta t_{N 36} \\
{[\mathrm{~h}]}\end{array}$ & $\begin{array}{l}G R_{1-3} \\
{[\mathrm{~nm} / \mathrm{h}]}\end{array}$ & $\begin{array}{l}\Delta t_{N 36} \\
{[\mathrm{~h}]}\end{array}$ & $\begin{array}{l}G R_{1-3} \\
{[\mathrm{~nm} / \mathrm{h}]}\end{array}$ & $\begin{array}{l}\Delta t_{N 36} \\
{[\mathrm{~h}]}\end{array}$ & $\begin{array}{l}G R_{1-3} \\
{[\mathrm{~nm} / \mathrm{h}]}\end{array}$ \\
\hline Mean & 2 & 1.2 & 1.5 & 1.5 & 1.4 & 3.1 \\
\hline Median & 1.7 & 1.2 & 1.5 & 1.3 & 1.5 & 1.2 \\
\hline Min & 1.0 & 0.5 & 0.7 & 0.9 & 0.0 & 0.6 \\
\hline Max & 4.1 & 2.1 & 2.3 & 2.7 & 3.5 & 10 \\
\hline
\end{tabular}

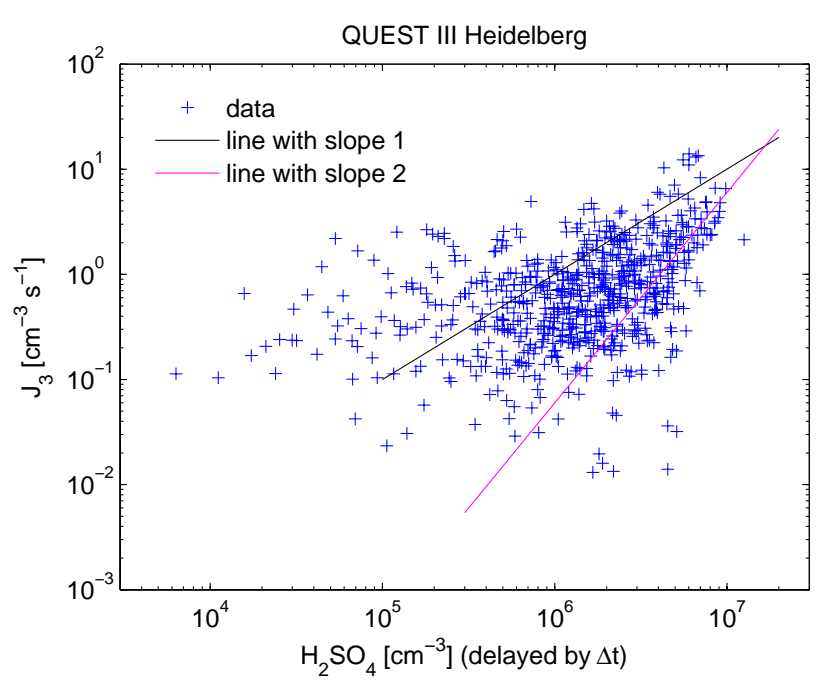

Fig. 5a. The formation rate $J_{3}$ estimated from particle measurements versus the sulphuric acid concentration during the QUEST III campaign in Heidelberg. Sulphuric acid concentrations have been delayed by the fitted time lags. Lines with slopes 1 and 2 (corresponding to values 1 and 2 in the exponent $n_{J 3}$ ) are indicated to guide the eye.

days the exponent was 1.5 , and on $2(20 \%)$ days $n_{J 3}$ had the value of 2 . On one day the exponent corresponding to the best correlation was approximately 3. In Hyytiälä, the results were similar, on 3 days $(17 \%) n_{J 3}$ was approximately 1 , on $2(11 \%)$ days $n_{J 3}$ had the value 1.5 , and on $8(44 \%)$ days the exponent was 2 . On $5(28 \%)$ days $n_{J 3}$ was 2.5 . The time delays $\Delta t_{J 3}$ had a mean value of $0.8 \mathrm{~h}$ and a median $0.7 \mathrm{~h}$ in

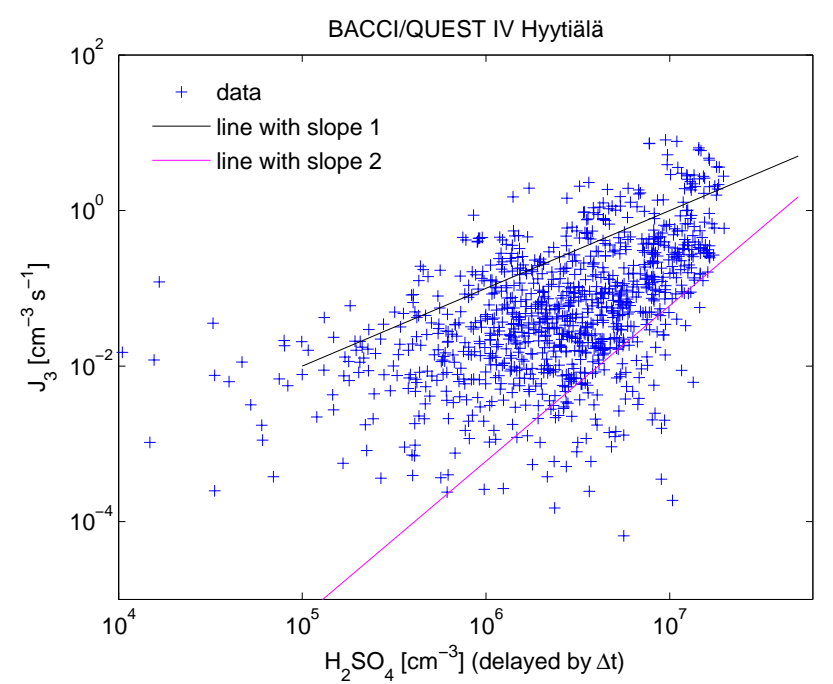

Fig. 5b. The formation rate $J_{3}$ estimated from particle measurements versus the sulphuric acid concentration during the BACCI/QUEST IV campaign in Hyytiälä. Sulphuric acid concentrations have been delayed by the fitted time lags. Lines with slopes 1 and 2 (corresponding to values 1 and 2 in the exponent $\left.n_{J 3}\right)$ are indicated to guide the eye.

Heidelberg. In Hyytiälä, the corresponding values were $0.7 \mathrm{~h}$ and $0.3 \mathrm{~h}$.

The formation rate $J_{3}$ is plotted versus the sulphuric acid concentration in Figs. 5a and b for Heidelberg and Hyytiälä, respectively. The plots include all data points between 06:00 a.m. and 06:00 p.m. for all event days during the 
campaigns. Lines with slopes 1 and 2 (corresponding to the values 1 and 2 for the exponent $n_{J 3}$ ) are also indicated in the figures to guide the eye. Similar result has been reported by Weber et al. (1996) for measurements at a marine and a continental site, where the exponent $n_{J 3}$ was also between 1 and 2.

When calculating the $J_{3}$ with Eq. (6), the numerical differentiation of the $N_{3-6}$ data results in relatively large fluctuations in $J_{3}$, despite the applied smoothing algorithm. The $J_{3}$ data therefore includes negative values, which must be left out from the analysis. The reasoning for this is that if we assume particles to be lost only due to coagulation, and not due to evaporation (i.e. $G R_{3}$ in Eq. (6) is assumed to be positive), $J_{3}$ should be positive. Due to the resulting gaps in $J_{3}$ data, the correlation coefficients between $J_{3}$ and $\left[\mathrm{H}_{2} \mathrm{SO}_{4}\right]^{n_{J 3}}$ are not as high as in case of $N_{3-6}$. However, the correlation between $J_{3}$ and $\left[\mathrm{H}_{2} \mathrm{SO}_{4}\right]^{n_{J 3}}$ is clear, the correlation coefficients being $0.37-0.85$ in Heidelberg, and $0.54-0.98$ in Hyytiälä. In $J_{3}$ there were often distinct peaks that corresponded clearly to peaks in $\left[\mathrm{H}_{2} \mathrm{SO}_{4}\right]$ data. It should be noted that these peaks do not necessarily coincide with peaks in $N_{3-6}$, because the $J_{3}$ is derived from $N_{3-6}$ using Eq. (6). This observation gives us further confidence that there is a fundamental connection between the new particle formation rates and sulphuric acid, which can be formulated e.g. according to Eqs. (2) and (3).

\subsubsection{Comparison of the exponents and time delays for $N_{3-6}$ and $J_{3}$}

The time delays $\Delta t$ and exponents for both $N_{3-6}$ and $J_{3}$ fittings are listed in Tables 3a (Heidelberg) and 3b (Hyytiälä). It can be observed that the time delays between $J_{3}$ and sulphuric acid are consistently smaller than the time delays for $N_{3-6}$. The mean time delays for $J_{3}$ in Hyytiälä and Heidelberg are $0.7 \mathrm{~h}$ and $0.8 \mathrm{~h}$, respectively, while the values for $N_{3-6}$ are $1.4 \mathrm{~h}$ and $1.5 \mathrm{~h}$, respectively. The difference in time delays $\Delta t_{N 36}$ and $\Delta t_{J 3}$ is on average $0.7 \mathrm{~h}$. The result is reasonable, since the formation rate $J_{3}$ is essentially the differential of $N_{3-6}$. This implies that a rise in the $N_{3-6}$ is always preceded by a rise in $J_{3}$.

In this study we have used the time delay $\Delta t_{N 36}$ instead of $\Delta t_{J 3}$ for estimating the mean growth rates for $1-3 \mathrm{~nm}$ particles during new particle formation (see Tables $3 a$ and $b$ ). There are several reasonings for this choice. First, $\Delta t_{N 36}$ can be determined directly and reliably from the data, whereas $J_{3}$ needs to be calculated using the measured data. Second, using $\Delta t_{N 36}$ makes our results comparable with the available literature, where similar methods have been used (Weber et al., 1997; Fiedler et al., 2005; Sihto et al., 2006). Additionally, preliminary calculations with an aerosol dynamics model (UHMA, see Korhonen et al., 2004) imply that the growth rate determined from the time delay of $N_{3-6}$ is closer to the real particle growth rates (which are not constant, either in time or for all 1-3 nm particles) as compared with the one calculated from the time delay of $J_{3}$. It should be borne in mind, however, that if the growth rate of $1-3 \mathrm{~nm}$ particles would be constant, it would be directly obtained from the time difference between $J_{1}$ and $J_{3}$, or if $J_{1} \propto\left[\mathrm{H}_{2} \mathrm{SO}_{4}\right]$, between $\left[\mathrm{H}_{2} \mathrm{SO}_{4}\right]$ and $J_{3}$. Also the $1-3 \mathrm{~nm}$ growth rates determined from ion measurements are close to the growth rates obtained from $\Delta t_{N 36}$.

The exponent in the $J_{3}$ correlation was observed to be greater than or or equal to the exponent in $N_{3-6}$ correlation ( $n_{J 3} \geq n_{N 36}$, see Tables $3 \mathrm{a}$ and $\left.\mathrm{b}\right)$. In Hyytiälä BACCI/QUEST IV data set, on 7 days of the total of 18 new particle formation days the exponent $n_{J 3}$ is higher by approximately 0.5 compared with $n_{N 36}$ and by 1.0 on 4 days. Similar trend is observed in Heidelberg, where the exponent increases by 0.5 on 4 days and by 1.0 on 3 days, staying the same on 3 days. The change in the exponent when calculating back from $N_{3-6}$ to $J_{3}$ is again related to the fact that $N_{3-6}$ is an integral quantity of $J_{3}: N_{3-6}$ increases less steeply with time compared to $J_{3}$, resulting in smaller exponent for $N_{3-6}$ when fitted with sulphuric acid data.

To further investigate the relationship of the exponents in the $N_{3-6}$ and $J_{3}$ correlations, we used the derived analytical formula (Eq. 8, see also Appendix A) to estimate the exponent of $J_{3}$ correlation if the exponent for $N_{3-6}$ is known. We can now carry on an exemplary calculation for one day, substituting typical ambient values in Hyytiälä conditions for the condensation and coagulation sinks, for instance, $C S=1.0 \times 10^{-3} \mathrm{~s}^{-1}$ and $\mathrm{CoagS}=0.6 \times 10^{-4} \mathrm{~s}^{-1}$. The coefficient for the sulphuric acid formation rate can be set to e.g. $Q_{0}=1.0 \times 10^{7} \mathrm{~cm}^{-3} \mathrm{~h}^{-1}$ (corresponding to a maximum sulphuric acid concentration of approximately $\left.5.5 \times 10^{6} \mathrm{~cm}^{-3}\right)$. The sulphuric acid concentration obtained with this production rate (Eq. A8 in Appendix A) is presented in Fig. 6a. First, we used the maximum growth rate from BACCI/QUEST IV, $G R_{1-3}=10 \mathrm{~nm} / \mathrm{h}$. According to Kulmala et al. (2001b) and Lehtinen and Kulmala (2003) the factor $\alpha$ now has the value of approximately $1.8 \times 10^{-7} \mathrm{~nm} / \mathrm{h} \cdot \mathrm{cm}^{3}$. Thus the sulphuric acid would explain at maximum a growth rate of about $1.0 \mathrm{~nm} / \mathrm{h}$, therefore leading to $\beta=9.0 \mathrm{~nm} / \mathrm{h}$. The terms $B\left[\mathrm{H}_{2} \mathrm{SO}_{4}\right]^{n_{N 36}-1}, D\left[\mathrm{H}_{2} \mathrm{SO}_{4}\right]^{n_{N 36}}$ and $E\left[\mathrm{H}_{2} \mathrm{SO}_{4}\right]^{n_{N 36}+1}$ normalized with the factor $C$ (Eq. A2) and the total normalized formation rate expressed with Eq. (8) are plotted in Fig. 6b. Second, the total growth rate was assumed to be $0.6 \mathrm{~nm} / \mathrm{h}$, corresponding to the minimum growth rate observed during the BACCI/QUEST IV. In this case, the maximum sulphuric acid concentration could explain the growth rate totally, and therefore $\beta=0$. The terms $B\left[\mathrm{H}_{2} \mathrm{SO}_{4}\right]^{n_{N 36}-1}, D\left[\mathrm{H}_{2} \mathrm{SO}_{4}\right]^{n_{N 36}}$ and $E\left[\mathrm{H}_{2} \mathrm{SO}_{4}\right]^{n_{N 36}+1}$ and the total $J_{3}$ for this case are presented in Fig. 6c. In these calculations we assumed $n_{N 36}=2$; the case with $n_{N 36}=1$ gives qualitatively similar results.

The calculations indicate that the term with the exponent $n_{N 36}$ is clearly dominating in our first exemplary case, where only about one tenth of the growth rate can be explained by sulphuric acid. In the second case, on the other hand, when 
Table 3a. The fitted time delays and categorised exponents for $N_{3}-6$ and $J_{3}$ correlations with sulphuric acid for each new particle formation event day during QUEST III (Heidelberg). The exponents fitted to $J_{3}$ are consistently larger than the exponents fitted to $N_{3}-6$. Correspondingly the time delays of $J_{3}$ are smaller than in the case of $N_{3-6}$. During some days $\left(^{*}\right)$ the $J_{1}$ data contained peaks corresponding to exponent 2 even though the general behaviour during the day would correspond to $n_{J 1}=1$.

\begin{tabular}{llllllll}
\hline Date & DOY & $\begin{array}{l}\Delta t_{N 36} \\
{[\mathrm{~h}]}\end{array}$ & $\begin{array}{l}G R_{1-3} \\
{[\mathrm{~nm} / \mathrm{h}]}\end{array}$ & $\begin{array}{l}\Delta t_{J 3} \\
{[\mathrm{~h}]}\end{array}$ & $n_{N 36}$ & $n_{J 3}$ & $n_{J 1}$ \\
\hline 14.3. & 74 & 1.5 & 1.3 & 1.0 & 1.0 & 2.0 & 2.0 \\
15.3. & 75 & 0.7 & 2.9 & 0.3 & 1.0 & 1.0 & - \\
16.3. & 76 & 1.3 & 1.5 & 0.8 & 1.5 & 2.0 & - \\
18.3. & 78 & 1.5 & 1.3 & 1.0 & 2.0 & 3.0 & - \\
19.3. & 79 & 1.0 & 2.0 & 0.3 & 1.0 & 2.0 & 2.0 \\
21.3. & 81 & 1.7 & 1.2 & 0.7 & 1.0 & 1.0 & 1.0 \\
22.3. & 82 & 1.7 & 1.2 & 0.7 & 1.0 & 1.5 & $1.0^{*}$ \\
27.3. & 87 & 1.2 & 1.7 & 0.5 & 1.0 & 1.5 & $1.0^{*}$ \\
30.3. & 90 & 2.2 & 1.3 & 1.3 & 1.5 & 2.0 & 2.0 \\
2.4. & 93 & 2.3 & 0.9 & 1.8 & 1.5 & 1.5 & - \\
& & & & & & & \\
\hline & Mean & 1.5 & 1.5 & 0.8 & & & \\
& Median & 1.5 & 1.3 & 0.7 & & & \\
& Min & 0.7 & 0.9 & 0.3 & & & \\
\hline
\end{tabular}

* Peaks with exponent 2

Table 3b. The fitted time delays and the categorised exponents for $N_{3-6}$ and $J_{3}$ correlations with sulphuric acid for new particle formation days during BACCI/QUEST IV campaign (Hyytiälä). Consistently with Heidelberg data, the exponents $n_{J 3}$ are larger than the exponents $n_{N 36}$. Also the time delays of $J_{3}$ are smaller than in the case of $N_{3-6}$. For the explanations of (*), see Table $3 \mathrm{a}$.

\begin{tabular}{llllllll}
\hline Date & DOY & $\begin{array}{l}\Delta t_{N 36} \\
{[\mathrm{~h}]}\end{array}$ & $\begin{array}{l}G R_{1-3} \\
{[\mathrm{~nm} / \mathrm{h}]}\end{array}$ & $\begin{array}{l}\Delta t_{J 3} \\
{[\mathrm{~h}]}\end{array}$ & $n_{N 36}$ & $n_{J 3}$ & $n_{J 1}$ \\
\hline 12.4. & 102 & 0.2 & 10 & 0 & 1.0 & 2.0 & $1.0^{*}$ \\
13.4. & 103 & 1.0 & 2.0 & 0.3 & 1.0 & 1.5 & $1.0^{*}$ \\
16.4. & 106 & 1.2 & 1.7 & 0.7 & 1.0 & 1.0 & $1.0^{*}$ \\
17.4. & 107 & 0.5 & 4.0 & 0 & 2.0 & 2.0 & 2.0 \\
18.4. & 108 & 2.3 & 0.9 & 1.3 & 2.0 & 2.5 & 2.0 \\
24.4. & 114 & 3.5 & 0.6 & 3.0 & 1.5 & 2.0 & 2.0 \\
25.4. & 115 & 2.0 & 1.0 & 0.7 & 1.0 & 2.0 & 2.0 \\
26.4. & 116 & 2.0 & 1.0 & 1.5 & 2.0 & 2.5 & 2.0 \\
27.4. & 117 & 0.3 & 6.7 & 0 & 2.0 & 2.0 & 2.0 \\
30.4. & 120 & 2.0 & 1.0 & 0.2 & 1.5 & 2.0 & 2.0 \\
2.5. & 122 & 2.3 & 0.9 & 2.0 & 1.0 & 1.5 & 2.0 \\
3.5. & 123 & 0 & - & 0 & 2.5 & 2.5 & 2.0 \\
8.5. & 128 & 0.3 & 6.7 & 0 & 1.0 & 1.0 & $1.0^{*}$ \\
11.5. & 131 & 2.0 & 1.0 & 1.5 & 1.0 & 2.0 & 2.0 \\
12.5. & 132 & 3.0 & 0.7 & 1.8 & 1.0 & 2.0 & $1.0^{*}$ \\
13.5. & 133 & 1.7 & 1.2 & 0 & 1.0 & 1.0 & $1.0^{*}$ \\
14.5. & 134 & 0.2 & 10 & 0 & 2.0 & 2.5 & 2.0 \\
16.5. & 136 & 0.7 & 2.9 & 0.2 & 2.5 & 2.5 & 2.0 \\
\hline & & & & & & & \\
\hline & Mean & 1.4 & 3.1 & 0.7 & & & \\
& Median & 1.5 & 1.2 & 0.3 & & & \\
\hline & Min & 0 & 0.6 & 0 & & & \\
\hline
\end{tabular}

* Peaks with exponent 2 
all of the growth can be explained by the sulphuric acid concentration, the $n_{N 36}+1$-dependent term dominates. In both cases the $n_{N 36}-1$-dependent term is of minor importance. Thus the simple analytical derivation suggests that $n_{N 36^{-}}$ $1 \leq n_{J 3} \leq n_{N 36}+1$. The same relation was observed from the data: the $n_{J 3}$ was always larger than or equal to $n_{N 36}$, with a maximum difference of unity. The derived result indicates that the difference between the exponents $n_{N 36}$ and $n_{J 3}$ is clearly larger, the larger the contribution of sulphuric acid to the 1-3 nm particle growth (see Fig. 6).

\subsection{Nucleation coefficients $A$ and $K$ during new particle formation}

The two atmospheric nucleation mechanisms - the activation of stable clusters and kinetic nucleation by sulphuric acid were tested by comparing the formation rates $J_{1}$ and $J_{3}$ calculated from the sulphuric acid concentration according to Eqs. (2) and (3) with those estimated from the particle measurements. The actual values for the nucleation coefficients $A$ and $K$ were determined with least squares fits. In the relationship $J_{1} \propto\left[\mathrm{H}_{2} \mathrm{SO}_{4}\right]^{n_{J 1}}$ the exponent is expected to be discrete, with $n_{J 1}=1$ in the case of particle formation by cluster activation, and $n_{J 1}=2$ in the case of kinetic nucleation. We also calculated the nucleation rate with the exponent $n_{J 1}=3$ for each day as a representative of thermodynamically limited nucleation scheme.

The nucleation coefficients $A$ and $K$ were determined for all event days during QUEST III and IV campaings. We determined both coefficients for every day, since there were days when the exponents, time lags or kinetic coefficients seemed to vary during the day. There are several possible reasons for this, such as changes in the amount of condensable vapours and particle growth rates, or different nucleation mechanisms taking place simultaneously. The results are summarized in Table 4, where also values for the QUEST II campaign are listed for comparison. In Hyytiälä, during the QUEST IV campaign the activation coefficients varied from $3.3 \times 10^{-8} \mathrm{~s}^{-1}$ to $2.0 \times 10^{-6} \mathrm{~s}^{-1}$ with a median value of $2.4 \times 10^{-7} \mathrm{~s}^{-1}$. Kinetic coefficients were in the range $2.4 \times 10^{-15}-1.8 \times 10^{-13} \mathrm{~cm}^{3} \mathrm{~s}^{-1}$ with a median of $3.2 \times 10^{-14} \mathrm{~cm}^{3} \mathrm{~s}^{-1}$. These values are somewhat lower compared to the QUEST II campaign, with a larger range from the minimum to the maximum. In Heidelberg the coefficients were significantly higher: the activation coefficients varied from $2.6 \times 10^{-6} \mathrm{~s}^{-1}$ to $3.5 \times 10^{-4} \mathrm{~s}^{-1}$ with a median of $1.1 \times 10^{-5} \mathrm{~s}^{-1}$, and kinetic coefficients from $3.7 \times 10^{-13} \mathrm{~cm}^{3} \mathrm{~s}^{-1}$ to $1.3 \times 10^{-10} \mathrm{~cm}^{3} \mathrm{~s}^{-1}$ with a median of $2.3 \times 10^{-11} \mathrm{~cm}^{3} \mathrm{~s}^{-1}$. These values are more than an order of magnitude greater than the coefficients in Hyytiälä.

Possible reasons for the difference between the campaigns could be for instance different concentration or composition of the activated clusters, different variety or amount of condensable vapours, or other environmental factors related to e.g. the meteorological conditions or the condensational sink.

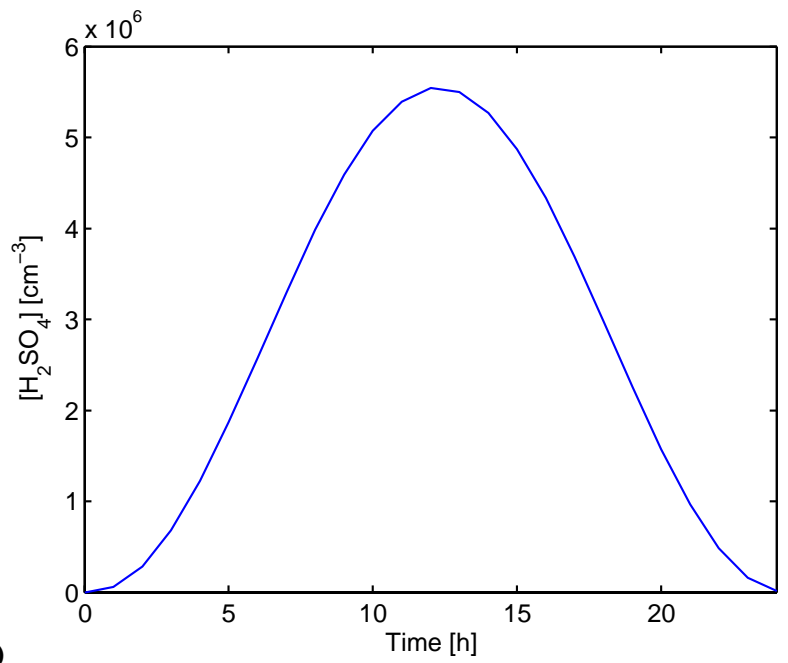

(a)

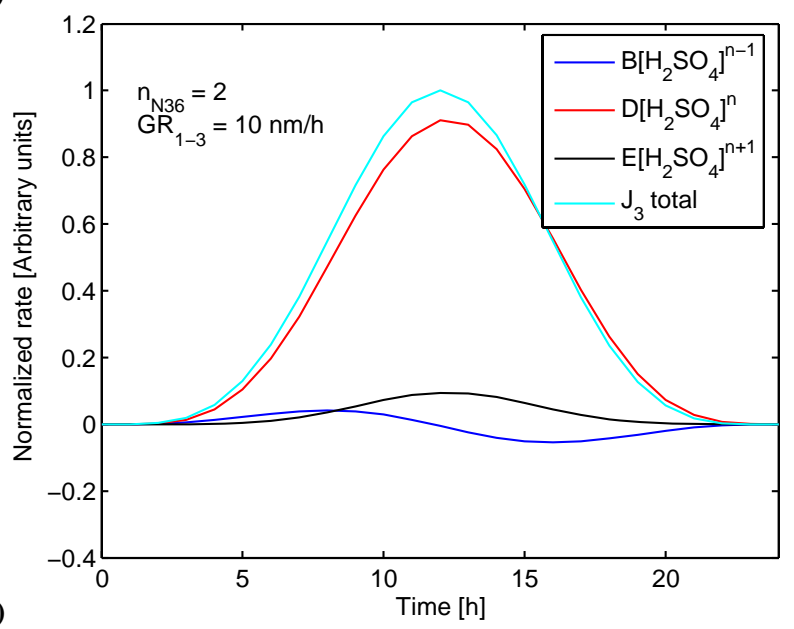

(b)

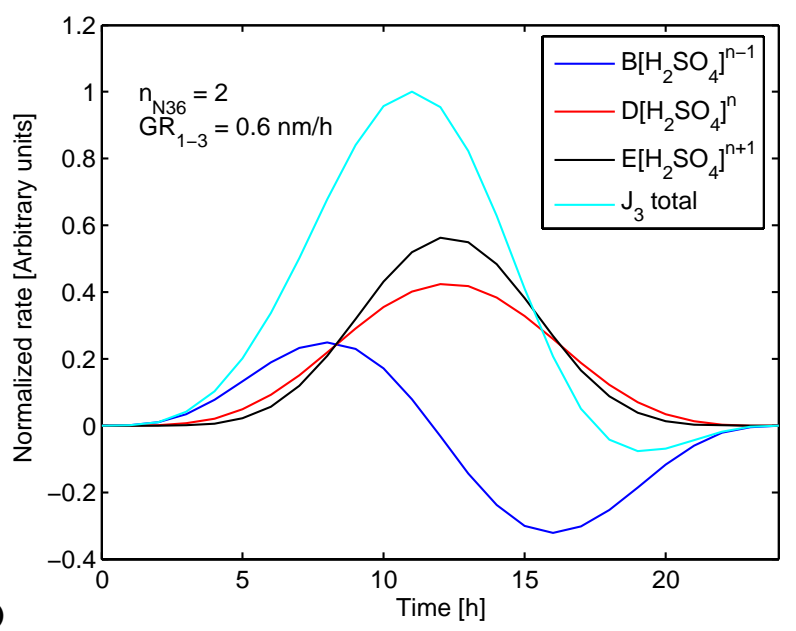

Fig. 6. The analytical estimations for the formation rate. (a) The sulphuric acid concentration calculated from the sinusoidal production rate; (b) The different terms in Eq. (8) and the total calculated $J_{3}$, using the growth rate of $10 \mathrm{~nm} / \mathrm{h}$; (c) The same as (b) but with the growth rate of $0.6 \mathrm{~nm} / \mathrm{h}$. 
Table 4. The average values for the activation and kinetic coefficients $A$ and $K$ during new particle formation in the QUEST II-IV campaigns.

\begin{tabular}{lllllll}
\hline & \multicolumn{2}{l}{ Hyytiälä QUEST II } & \multicolumn{2}{l}{ Heidelberg QUEST III } & \multicolumn{2}{l}{ Hyytiälä BACCI/QUEST IV } \\
& $A$ & $K$ & $A$ & $K$ & $A$ & $K$ \\
& {$[1 / \mathrm{s}]$} & {$\left[\mathrm{cm}^{3} / \mathrm{s}\right]$} & {$[1 / \mathrm{s}]$} & {$\left[\mathrm{cm}^{3} / \mathrm{s}\right]$} & {$[1 / \mathrm{s}]$} & {$\left[\mathrm{cm}^{3} / \mathrm{s}\right]$} \\
\hline Mean & $1.7 \mathrm{E}-06$ & $5.7 \mathrm{E}-13$ & $7.7 \mathrm{E}-05$ & $2.3 \mathrm{E}-11$ & $3.5 \mathrm{E}-07$ & $5.5 \mathrm{E}-14$ \\
Median & $1.0 \mathrm{E}-06$ & $4.5 \mathrm{E}-13$ & $1.1 \mathrm{E}-05$ & $3.9 \mathrm{E}-12$ & $2.4 \mathrm{E}-07$ & $3.2 \mathrm{E}-14$ \\
25\%-quartile & $8.0 \mathrm{E}-07$ & $3.0 \mathrm{E}-13$ & $6.1 \mathrm{E}-06$ & $1.5 \mathrm{E}-12$ & $7.1 \mathrm{E}-08$ & $1.7 \mathrm{E}-14$ \\
75\%-quartile & $2.8 \mathrm{E}-06$ & $7.8 \mathrm{E}-13$ & $6.7 \mathrm{E}-05$ & $1.2 \mathrm{E}-11$ & $2.8 \mathrm{E}-07$ & $9.2 \mathrm{E}-14$ \\
Min & $4.0 \mathrm{E}-07$ & $2.0 \mathrm{E}-13$ & $2.6 \mathrm{E}-06$ & $3.7 \mathrm{E}-13$ & $3.3 \mathrm{E}-08$ & $2.4 \mathrm{E}-15$ \\
Max & $6.0 \mathrm{E}-06$ & $1.4 \mathrm{E}-12$ & $3.5 \mathrm{E}-04$ & $1.3 \mathrm{E}-10$ & $2.0 \mathrm{E}-06$ & $1.8 \mathrm{E}-13$ \\
\hline
\end{tabular}

To find explanations for this differences, we looked for correlations between the nucleation coefficients and ambient variables such as temperature, relative humidity, condensation sink, as well as sulphuric acid and ammonia concentrations. The only statistically significant correlation we found for the nucleation coefficients was with the condensation sink, for which the correlation coefficient was 0.50 for $A$ and 0.35 for $K$. For instance, no clear temperature dependence was observed. The correlations were calculated for the whole data set containing data from the QUEST II-IV campaigns, and medians from 09:00 a.m. to 15:00 p.m. were used for the ambient variables. One aspect that might have some effect on the results is that with the present method we can estimate the values of $A$ and $K$ only on the new particle formation event days, combined with the fact that we cannot detect particles below $3 \mathrm{~nm}$ with the current instruments. Because of the higher condensation sink in Heidelberg, there might be more days when new particle formation starts but the particles do not grow to $3 \mathrm{~nm}$ before scavenging to pre-existing particles. This means that compared to Hyytiälä, the particles have to grow faster and/or the values of $\mathrm{A}$ and $\mathrm{K}$ need to be higher in Heidelberg to really observe a typical new particle formation event with continuous growth above the detection limit of the DMPS.

Exponents $n_{J 1}$, which can be termed also as the exponents of the nucleation, were determined simply by choosing the curve $\left(n_{J 1}=1,2\right.$ or 3$)$ that gives the best correspondence to the $J_{1}$ estimated from the particle measurements. The values are listed in Table 3. Kulmala et al. (2006) have shown that theoretically always applies $n_{J 1} \leq n_{J 3}$. This condition was always satisfied in this study as well (see Table 3 ). This result, along with the fact that $n_{J 3}$ never exceeded 3 , suggest that the activation of stable clusters and/or kinetic nucleation are possible nucleation mechanisms present in atmospheric particle formation. On some days in Heidelberg, when a clear rise in $J_{3}$ was missing or the data were heavily scattered, we were not able to specify the exponent $n_{J 1}$.

\subsection{Non-events and undefined days}

During the BACCI/QUEST IV campaign in Hyytiälä there were 17 days with no significant new particle formation when also sulphuric acid measurements were performed; of these 9 were classified as "non-event days" and 8 as "undefined". This data allows us to test the framework of activation and kinetic nucleation during days with no new particle formation using the determined nucleation coefficients. We calculated the nucleation rate $J_{1}$ from the sulphuric acid concentration according to activation hypothesis (Eq. 2) using the median value during BACCI/QUEST IV for $A$, thus $A=2.4 \times 10^{-7} \mathrm{~s}^{-1}$. The $J_{1}$ was scaled to the formation rate $J_{3}$ by Eq. (7) using the median value for $G R_{1-3}$ (see Table 3 ). The condensation sink was calculated for each day in the same manner as for the event days from the background aerosol distribution in a running window of $[t-\Delta t, t]$. The calculations were repeated using the kinetic coefficient $K$, yielding similar results.

The median values of $J_{1}$ on days with no new particle formation, calculated according to the activation hypothesis, were similar to the values on the event days (approximately $0.2 \mathrm{~cm}^{-3} \mathrm{~s}^{-1}$ ). The maximum nucleation rates during the day showed a clearer difference being approximately $0.9 \mathrm{~cm}^{-3} \mathrm{~s}^{-1}$ on non-event and undefined days compared to $3.4 \mathrm{~cm}^{-3} \mathrm{~s}^{-1}$ on event days. Thus on the days with no new particle formation the peak value in sulphuric acid (i.e. in the nucleation rate) was significantly smaller than on the event days.

When considering the formation rates $J_{3}$, the event days differed clearly from the non-event days (see Fig. 7a for the Hyytiälä data). On 6 non-event days out of 9, the median of the calculated $J_{3}$ was approximately an order of magnitude lower compared to the median $J_{3}$ on event days. The median of $J_{3}$ on the event days was about $1.7 \times 10^{-2} \mathrm{~cm}^{-3} \mathrm{~s}^{-1}$ but on non-event days only $2.0 \times 10^{-3} \mathrm{~cm}^{-3} \mathrm{~s}^{-1}$. Also the maximum $J_{3}$ values showed a difference of the same magnitude, being $4.3 \times 10^{-1} \mathrm{~cm}^{-3} \mathrm{~s}^{-1}$ on event days and $1.8 \times 10^{-2} \mathrm{~cm}^{-3} \mathrm{~s}^{-1}$ on the non-event days. Since the differences were not as clear in the $J_{1}$ values, the main reason for the small predicted $J_{3}: \mathrm{s}$ on the nonevent days was 


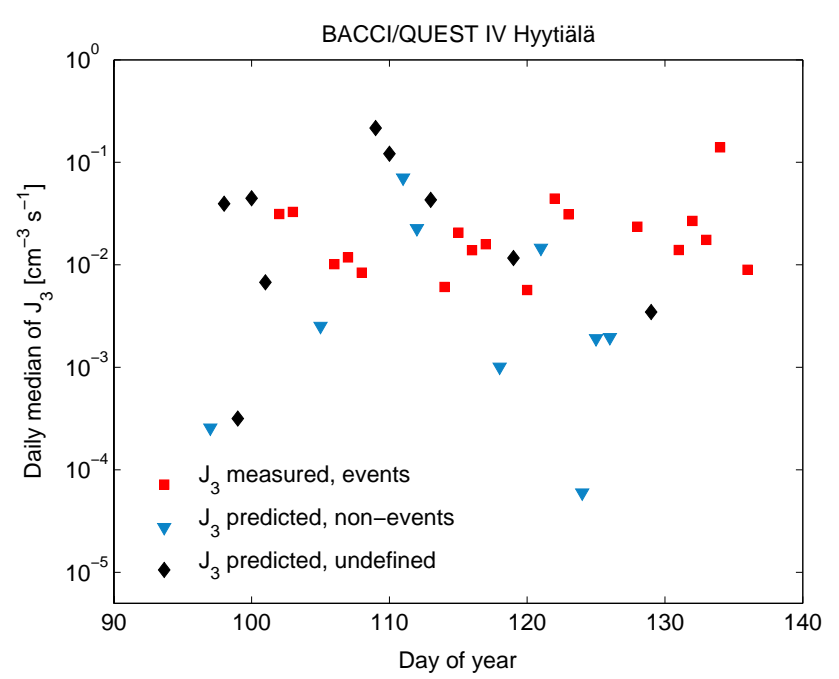

Fig. 7a. The median particle formation rates at $3 \mathrm{~nm}$ for BACCI/QUEST IV, Hyytiälä. The red squares refer to the $J_{3}$ values calculated from the DMPS data for the particle formation events. The blue triangles and the black diamonds show the values predicted for non-event and undefined days from the sulphuric acid data according to cluster activation hypothesis.

most probably the condensation sink, which was taken into account when scaling from $J_{1}$ to $J_{3}$ by the exponential formula (Eq. 7). Also a slow growth rate could be a reason for a small $J_{3}$, but its effect cannot be studied in detail because the growth rate naturally cannot be determined for the nonevent days. In any case, the effect of the $C S$ is expected to be more pronounced compared to $G R_{1-3}$, because the variation in $C S$ is much larger than in the growth rate.

In contrast to the non-event days, the $J_{3}$ :s on the undefined days in Hyytiälä lie mostly in the same range as on the event days, as seen in Fig. 7a. The median of $J_{3}$ on undefined days was $4.0 \times 10^{-2} \mathrm{~cm}^{-3} \mathrm{~s}^{-1}$ whereas on the event days it was $1.7 \times 10^{-2} \mathrm{~cm}^{-3} \mathrm{~s}^{-1}$. In the maximum values of $J_{3}$ we see a larger difference, with $8.5 \times 10^{-2} \mathrm{~cm}^{-3} \mathrm{~s}^{-1}$ on the undefined and $4.2 \times 10^{-1} \mathrm{~cm}^{-3} \mathrm{~s}^{-1}$ on the event days. This might indicate that the characteristics of the undefined days typically resemble more those of event days than non-event days. There may be new particle formation taking place also on the undefined days, but due to e.g. the meteorological situation, lack of continuous growth or rapidly changing air masses they are classified as undefined.

Similar analysis as described above for Hyytiälä was conducted for the Heidelberg data as well. Due to the high background concentrations and the gaps in sulphuric acid data, there were only two analysable non-event days. The atmospheric nucleation rates $J_{1}$ on these days were $4.7 \mathrm{~cm}^{-3} \mathrm{~s}^{-1}$ and $5.7 \mathrm{~cm}^{-3} \mathrm{~s}^{-1}$. On the undefined days, the median $J_{1}$ was $5.5 \mathrm{~cm}^{-3} \mathrm{~s}^{-1}$, and the corresponding value for the event days was $25.2 \mathrm{~cm}^{-3} \mathrm{~s}^{-1}$, resulting in a difference of approximately factor 5 . For the $J_{3}$ values the differences between event and non-event or undefined days were again more pro-

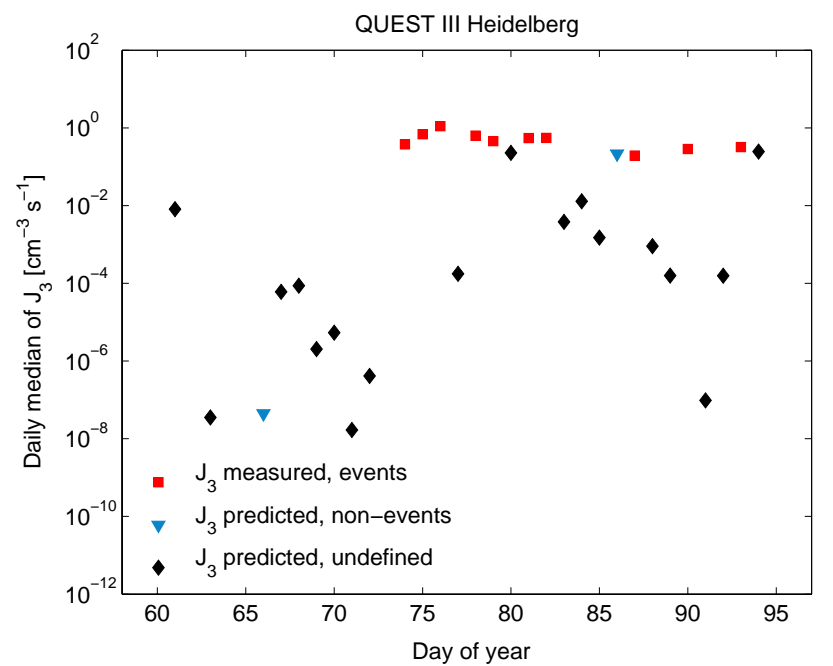

Fig. 7b. The median particle formation rates at $3 \mathrm{~nm}$ for QUEST III, Heidelberg. The red squares refer to the $J_{3}$ values calculated from the DMPS data for the particle formation events. The blue triangles and the black diamonds show the values predicted for non-event and undefined days from the sulphuric acid data according to cluster activation hypothesis.

nounced (see Fig. $7 \mathrm{~b}$ for the exact numbers), being typically about two orders of magnitude. In Heidelberg, also the undefined days differ clearly from the days with new particle formation.

As a summary, on most non-event days the formation rates predicted according to activation or kinetic nucleation hypotheses are so low that they would not lead to a new particle formation event. Thus in most cases the data from non-event days is consistent with the framework of activation or kinetic nucleation using the nucleation coefficients determined for the particle formation event days. There are some undefined days when the lack of new particle formation is probably due to the low sulphuric acid concentration. However, most often the sulphuric acid is not the limiting factor, but the condensation sink and a slow growth rate prevent particles from growing to sizes above $3-6 \mathrm{~nm}$.

\section{Conclusions}

We have studied the role of sulphuric acid in new particle formation and the initial particle growth during QUEST III and IV campaigns in Heidelberg and Hyytiälä, the preceding representing a polluted environment in Central Europe and the latter a rural boreal site in Finland.

We have quantitatively studied the dependencies of newly formed atmospheric particle concentrations and formation rates on sulphuric acid concentrations, using a computerbased fitting method. We have observed that both 3$6 \mathrm{~nm}$ particle concentrations and their formation rates have a power-law dependence on sulphuric acid concentrations 
(delayed with time lag $\Delta t_{N 36}$ or $\Delta t_{J 3}$ ), the typical powers being between 1 and 2 . This observation holds for both locations and is consistent with the results reported by Sihto et al. (2006) for QUEST II campaign in Hyytiälä. The exponents $1-2$, particularly in the relation between sulphuric acid and the 1 and $3 \mathrm{~nm}$ formation rates, strongly suggest that the activation of stable clusters and/or kinetic nucleation are probable mechanisms behind the observed atmospheric particle formation. Our analysis has concentrated on the role of sulphuric acid in the particle formation, and does not give direct information on what other compounds might be involved in the nucleation and growth processes. Possible candidates for these compounds are, for instance, ammonia and some organic molecules. However, the classical nucleation theories, such as the ternary nucleation theory involving water, sulphuric acid and ammonia, would predict exponents well above 2 and therefore do not seem as likely candidates to explain the atmospheric nucleation at the investigated sites. Also, no correlation between the measured ammonia concentration and new particle formation was observed. Organics play a significant role at least in the particle growth processes, the effect being encanced during the spring and summertime (see e.g. Kulmala et al., 2004b; Hirskko et al., 2005). However, further studies on the role of organics in particle formation are needed.

The time lags between sulphuric acid concentration and 3-6 nm particle concentrations and formation rates are rather similar at both locations and during all campaigns. However, the time lags observed earlier during the QUEST II campaign in Hyytiälä are slightly higher than the time lags observed in this study in both Hyytiälä (BACCI/QUEST IV) and Heidelberg (QUEST III), which indicates higher growth rates during BACCI/QUEST IV (mean $3.1 \mathrm{~nm} / \mathrm{h}$ ) and QUEST III (mean $1.5 \mathrm{~nm} / \mathrm{h}$ ) compared to QUEST II (mean $1.2 \mathrm{~nm} / \mathrm{h}$ ). The difference between the two springs in Hyytiälä is probably related to the fact that the BACCI/QUEST IV campaign was conducted later in spring (April-May) than the QUEST II campaign (March-April): the average growth rates of particles typically increase towards summer, presumably because the organics emitted by the forest start to contribute to the growth (see e.g. Dal Maso et al., 2005). The difference between QUEST II and QUEST III, even though both have been conducted in early spring, may be related to the higher background particle concentrations in Heidelberg: due to the higher coagulation sink, the particles have to grow faster to survive to detectable sizes.

In both places we have observed similar relations between the time lags and exponents in the sulphuric acid dependencies of the particle concentrations and formation rates: the time delay between sulphuric acid and particle formation rate tends to be shorter and the exponents higher than the corresponding variables for particle concentrations. The difference in the time delays can be explained by the differential relation between the formation rates and the concentrations. For the difference in the exponents $n_{N 36}$ and $n_{J 3}$ we have derived a simple analytical formula, which, if applied in typical ambient conditions produces similar relation as observed from the data. The main reason for the difference in the exponents is the significant participation of sulphuric acid in the initial particle growth.

The empirical nucleation coefficients $A$ (cluster activation) and $K$ (kinetic nucleation) have been determined for QUEST III and BACCI/QUEST IV data. The results have been compared with the values reported by Sihto et al. (2006) for Hyytiälä (QUEST II). Both coefficients are somewhat lower for BACCI/QUEST IV compared to QUEST II. The values for $A$ and $K$ in Heidelberg, on the other hand, are more than an order of magnitude higher than in Hyytiälä. The result is probably due to the different conditions at the measurement sites, such as the background particle concentrations, variety of condensable vapours or meteorological conditions. However, future studies are needed firstly to investigate the magnitude of the nucleation coefficients in different environments and secondly to pin down the physical reasons behind the variation. It is noteworthy that the kinetic coefficients in both locations are typically $2-4$ orders of magnitude lower than the collision rate of $\left[\mathrm{H}_{2} \mathrm{SO}_{4}\right]$ molecules in atmospheric conditions $\left(3 \times 10^{-10} \mathrm{~cm}^{3} \mathrm{~s}^{-1}\right)$. The result indicates that probability of a stable cluster formation upon the collision of two sulphuric acid molecules is significantly smaller than unity.

Theoretical predictions for atmospheric nucleation rates $J_{1}$ and particle formation rates at $3 \mathrm{~nm} J_{3}$ have been calculated for the days when no significant new particle formation and growth is observed. No significant difference between the $J_{1}$ values on particle formation event days and nonevent or undefined days is observed, which implies that the observed new particle formation and growth typically cannot be predicted from sulphuric acid concentrations alone. However, when the predicted $J_{3}$ values on non-event days are compared to the rates observed on particle formation event days, a much clearer difference (usually about an order of magnitude) is observed. Interestingly in Heidelberg, the same applies also for the undefined days, whereas in Hyytiälä the formation rates on undefined days are close to those of the event days. The results suggest that the main process limiting the particle formation and growth to detectable sizes is not the initial particle production by atmospheric nucleation of sulphuric acid, but rather the competition between the initial growth of the particles and the loss by scavenging to larger particles, as also speculated by e.g. Kulmala (2003). Our observations support the ideas of Kulmala et al. (2000, 2004b), where the atmospheric particle formation is proposed to be a two-step process consisting of 1) the nucleation forming thermodynamically stable clusters present all the time, and 2 ) the activation and growth of these clusters via vapour condensation.

In general, it can be concluded that the introduced simple models based on the cluster activation and kinetic nucleation mechanisms are able to predict the occurence of 
atmospheric particle formation events reasonably well, if the particle scavenging and growth are accounted for.

\section{Appendix A}

\section{Derivation of the analytical expression connecting $J_{3}$ and $n_{N 36}$}

According to Eq. (6) the formation rate of $3 \mathrm{~nm}$ particles can be written

$$
J_{3}=\frac{d N_{3-6}}{d t}+\operatorname{CoagS} \cdot N_{3-6}+\frac{G R_{1-3}}{3 \mathrm{~nm}} \cdot N_{3-6}
$$

According to observations, the particle concentration can be expressed as

$$
N_{3-6}=C\left[\mathrm{H}_{2} \mathrm{SO}_{4}\right]^{n_{N 36}} \text {. }
$$

If we now assume that the particle growth is partly by sulphuric acid, partly by some other condensing vapour (e.g. organics), the growth rate can be written as

$$
G R_{1-3}=\alpha\left[\mathrm{H}_{2} \mathrm{SO}_{4}\right]+\beta .
$$

Substituting Eqs. (A2) and (A3) to Eq. (A1), we get

$$
\begin{aligned}
J_{3}= & C\left[n_{N 36}\left[\mathrm{H}_{2} \mathrm{SO}_{4}\right]^{n_{N 36}-1} \cdot \frac{\mathrm{d}\left[\mathrm{H}_{2} \mathrm{SO}_{4}\right]}{\mathrm{d} t}+\right. \\
& \operatorname{CoagS} \cdot\left[\mathrm{H}_{2} \mathrm{SO}_{4}\right]^{n_{N 36}}+ \\
& \left.\frac{\beta}{3 \mathrm{~nm}} \cdot\left[\mathrm{H}_{2} \mathrm{SO}_{4}\right]^{n_{N 36}}+\frac{\alpha}{3 \mathrm{~nm}} \cdot\left[\mathrm{H}_{2} \mathrm{SO}_{4}\right]^{n_{N 36}+1}\right]
\end{aligned}
$$

On the other hand, we can write a balance equation for the $\left[\mathrm{H}_{2} \mathrm{SO}_{4}\right] \mathrm{l}$ :

$$
\frac{\mathrm{d}\left[\mathrm{H}_{2} \mathrm{SO}_{4}\right]}{\mathrm{d} t}=Q-C S \cdot\left[\mathrm{H}_{2} \mathrm{SO}_{4}\right],
$$

where $Q$ is the production rate of sulphuric acid. Let us now simply assume a sinusoidal production

$Q=Q_{0}[\sin (\omega t+k)+1]$,

so that the production has a maximum at noon and a minimum at midnight. Thus we can set $\omega=\pi / 12$ and $k=-\pi / 12$ (as $t$ is in hours). Equation (A6) can be substituted to Eq. (A5) to get a differential equation

$$
\frac{\mathrm{d}\left[\mathrm{H}_{2} \mathrm{SO}_{4}\right]}{\mathrm{d} t}=Q_{0}[\sin (\omega t+k)+1]-C S \cdot\left[\mathrm{H}_{2} \mathrm{SO}_{4}\right],
$$

which can be solved for $\left[\mathrm{H}_{2} \mathrm{SO}_{4}\right]$, yielding:

$$
\begin{aligned}
{\left[\mathrm{H}_{2} \mathrm{SO}_{4}\right]=} & Q_{0}\left\{\frac{C S}{\omega^{2}+C S^{2}} \sin (\omega t+k)-\right. \\
& \frac{\omega}{\omega^{2}+C S^{2}} \cos (\omega t+k)- \\
& {\left.\left[\frac{1}{C S}-\frac{C S}{\omega^{2}+C S^{2}}\right] e^{-C S \times t}+\frac{1}{C S}\right\} . }
\end{aligned}
$$

Combining Eqs. (A4), (A7) and (A8) and we can write $J_{3}$ as a function of $\left[\mathrm{H}_{2} \mathrm{SO}_{4}\right]$ :

$$
\begin{aligned}
J_{3}= & B \cdot\left[\mathrm{H}_{2} \mathrm{SO}_{4}\right]^{n_{N 36}-1}+ \\
& D \cdot\left[\mathrm{H}_{2} \mathrm{SO}_{4}\right]^{n_{N 36}}+E \cdot\left[\mathrm{H}_{2} \mathrm{SO}_{4}\right]^{n_{N 36}+1},
\end{aligned}
$$

where now

$$
\begin{aligned}
B & =C \cdot n_{N 36} Q_{0}\left[\frac{\omega}{C S} \cos (\omega t+k)+\frac{\omega^{2}}{C S^{2}}\left(e^{-C S \times t}-1\right)\right] \\
D & =C \cdot\left[n_{N 36} \cdot \frac{\omega^{2}+C S^{2}}{C S}-n_{N 36} C S+\operatorname{CoagS}+\beta \cdot \frac{1}{3 \mathrm{~nm}}\right] \\
E & =C \cdot \alpha \cdot \frac{1}{3 \mathrm{~nm}} .
\end{aligned}
$$

Acknowledgements. The authors kindly acknowledge the Academy of Finland, BACCI and the QUEST project.

Edited by: K. Hämeri

\section{References}

Anttila, T., Vehkamki, H., Napari, I., and Kulmala, M.: Effect of ammonium bisulphate formation on atmospheric water-sulphuric acid-ammonia nucleation, Bor. Env. Res., 10, 511-523, 2005.

Berndt, T., Böge, O., Stratmann, F., Heintzenberg, J., and Kulmala, M.: Rapid formation of new sulfuric acid particles at nearatmospheric conditions, Science, 307(5710), 698-700, 2005.

Cabada, J. C., Khlystov, A., Wittig, A. E., Pilinis, C., and Pandis, S. N.: Light scattering by fine particles during the Pittsburgh Air Quality Study: Measurements and modelling, J. Geophys. Res., 109, D16S03, doi:10.1029/2003JD004155, 2004.

Dal Maso, M., Kulmala, M., Riipinen, I., Wagner, R., Hussein, T., Aalto, P. P., and Lehtinen, K. E. J.: Formation and growth of fresh atmospheric aerosols: Eight years of aerosol size distribution data from SMEAR II, Hyytiälä, Finland, Boreal Environ. Res., 10, 323-336, 2005.

Donaldson, K., Xy, Li, and MacNee, W.: Ultra-fine (nanometer) particle-mediated lung injury, J. Aerosol. Sci., 29, 553-560, 1998.

Fiedler, V., Dal Maso, M., Boy, M., Aufmhoff, H., Hoffmann, J., Schuch, T., Birmili, W., Hanke, M., Uecker, J., Arnold, F., and Kulmala, M.: The contribution of sulphuric acid to atmospheric particle formation and growth: a comparison between boundary layers in Northern and Central Europe, Atmos. Chem. Phys., 5, 1773-1785, 2005, http://www.atmos-chem-phys.net/5/1773/2005/.

Hanke, M., Uecker, J., Reiner, T., and Arnold, F.: Atmospheric peroxy radicals: ROXMAS, a new mass-spectrometric methodology for speciated measurements of $\mathrm{HO}_{2}$ and Sigma $\mathrm{RO}_{2}$ and first results, Int. J. Mass Spectr., 213(2-3), 91-99, 2002.

Hari, P. and Kulmala, M.: Station for measuring ecosystematmosphere relations (SMEAR II), Boreal Environ. Res., 10, 315-322, 2005.

Hirsikko, A., Laakso, L., Hõrrak, U., Aalto, P. P., Kerminen, V.M., and Kulmala, M.: Annual and size dependent variation of 
growth rates and ion concentrations in boreal forest, Boreal Environ. Res., 10, 357-369, 2005.

Kerminen, V.-M. and Kulmala, M.: Analytical formulae connecting the "real" and the "apparent" nucleation rate and the nuclei number concentration for atmospheric nucleation events, J. Aerosol Sci., 33, 609-622, 2002.

Korhonen, H., Lehtinen, K. E. J., and Kulmala, M.: Multicomponent aerosol dynamics model UHMA: model development and validation, Atmos. Chem. Phys., 4, 757-771, 2004, http://www.atmos-chem-phys.net/4/757/2004/.

Korhonen, P., Kulmala, M., Laaksonen, A., Viisanen, Y., McGraw, R., and Seinfeld, J. H.: Ternary nucleation of $\mathrm{H}_{2} \mathrm{SO}_{4}, \mathrm{NH}_{3}$ and $\mathrm{H}_{2} \mathrm{O}$ in the atmosphere, J. Geophys. Res., 104, 26349-26353, 1999.

Kulmala, M., Pirjola, L., and Mäkelä, J.: Stable sulphate clusters as a source of new atmospheric particles, Nature, 404, 66-69, 2000.

Kulmala, M., Hämeri, K., Aalto, P. P., Mäkelä, J. M., Pirjola, L., Nilsson, E. D., Buzorius, G., Rannik, Ü, Dal Maso, M., Seidl, W., Hoffmann, T., Janson, R., Hansson, H.-C., Viisanen, Y., Laaksonen, A., and O'Dowd, C. D.: Overview of the international project on Biogenic aerosol formation in the boreal forest (BIOFOR), Tellus, 53B, 324-343, 2001a.

Kulmala, M., Dal Maso, M., Mäkelä, J. M., Pirjola, L., Väkevä, M., Aalto, P. P., Miikkulainen, P., Hämeri, K., and O’Dowd, C. D.: On the formation, growth and composition of nucleation mode particles, Tellus, 53B, 479-490, 2001b.

Kulmala, M.: How Particles Nucleate and Grow, Science, 302, 1000-1001, 2003.

Kulmala, M., Vehkamäki, H., Petäjä, T., Dal Maso, M., Lauri, A., Kerminen, V.-M., Birmili, W., McMurry, P. H.: Formation and growth rates of ultrafine atmospheric particles: A review of observations, J. Aerosol Sci., 35, 143-176, 2004a.

Kulmala, M., Laakso, L., Lehtinen, K. E. J., Riipinen, I., Dal Maso, M., Anttila, T., Kerminen, V.-M., Horrak, U., Vana, M., and Tammet, H.: Initial steps of aerosol growth, Atmos. Chem. Phys., 4, 2553-2560, 2004b.

Kulmala, M., Lehtinen, K. E. J., and Laaksonen, A.: Cluster activation theory as an explanation of the linear dependence of the formation rate of $3 \mathrm{~nm}$ particles and sulphuric acid concentrations, Atmos. Chem. Phys., 6, 787-793, 2006, http://www.atmos-chem-phys.net/6/787/2006/.

Laakso, L., Anttila, T., Lehtinen, K. E. J., Aalto, P. P., Kulmala, M., Hõrrak, U., Paatero, J., Hanke, M., and Arnold, F.: Kinetic nucleation and ions in boreal particle formation events, Atmos. Chem. Phys., 4, 2353-2366, 2004a.

Laakso, L., Petäjä, T., Lehtinen, K. E. J., Kulmala, M., Paatero, J., Hõrrak, U., Tammet, H., and Joutsensaari, J.: Ion production rate in a boreal forest based on ion, particle and radiation measurements, Atmos. Chem. Phys., 4, 1933-1943, 2004 b.
Lehtinen, K. E. J. and Kulmala, M.: A model for particle formation and growth in the atmosphere with molecular resolution in size, Atmos. Chem. Phys., 3, 251-257, 2003, http://www.atmos-chem-phys.net/3/251/2003/.

Lohmann, U. and Feichter, J.: Global indirect aerosol effects: a review, Atmos. Chem. Phys., 5, 715-737, 2005, http://www.atmos-chem-phys.net/5/715/2005/.

Lushnikov, A. A. and Kulmala, M.: Dimers in nucleating vapors, Phys. Rev. E., 58, 3157-3167, 1998.

McMurry, P. H. and Friedlander, S. K.: New particle formation in the presence of an aerosol, Atmos. Environ., 13, 1635-1651, 1979.

Napari, I., Kulmala, M., and Vehkamki, H.: Ternary nucleation of inorganic acids, ammonia, and water, J. Chem. Phys., 117, 84188425, 2002.

Ramanathan, V., Crutzen, P. J., Kiehl, J. T., and Rosenfeld, D.: Aerosol, climate, and the hydrological cycle, Science, 294, 2119-2124, 2001.

Sihto, S.-L., Kulmala, M., Kerminen, V.-M., Dal Maso, M., Petäjä, T., Riipinen, I., Korhonen, H., Arnold, F., Janson, R., Boy, M., Laaksonen, A., and Lehtinen, K. E. J.: Atmospheric sulphuric acid and aerosol formation: Implications from atmospheric measurements for nucleation and early growth mechanisms, Atmos. Chem. Phys., 6, 4079-4091, 2006,

http://www.atmos-chem-phys.net/6/4079/2006/.

Spracklen, D. V., Carslaw, K. S., Kulmala, M., Kerminen, V.-M., Mann, G. W., and Sihto, S.-L.: The contribution of boundary layer nucleation events to total particle concentrations on regional and global scales, Atmos. Chem. Phys., 6, 5631-5648, 2006, http://www.atmos-chem-phys.net/6/5631/2006/.

Stieb, D. M., Judek, S., and Burnett, R. T.: Meta-analysis of timeseries studies of air pollution and mortality: Effects of gases and particles and their influence of cause of death, age and season, J. Air Manage. Assoc., 52, 470-484, 2002.

Talbot, R. W., Vijgen, A. S., and Harriss, R. C.: Measuring tropospheric $\mathrm{HNO}_{3}$ : Problems and prospects for nylon filter and mist chamber techniques, J. Geophys. Res., 95, 7553-7561, 1990.

Weber, R. J., McMurry, P. H., Eisele, F. L., and Tanner, D. J.: Measurement of expected nucleation precursor species and 3-500 nm diameter particles at Mauna Loa observatory, Hawaii, J. Atmos. Sci., 52, 2242-2257, 1995.

Weber, R. J., Marti, J. J., McMurry, P. H., Eisele, F. L., Tanner, T. J., and Jefferson, A.: Measured atmospheric new particle formation rates : Implications for nucleation mechanisms, Chem. Eng. Commun., 151, 53-64, 1996.

Weber, R. J., Marti, J. J., McMurry, P. H., Eisele, F. L., Tanner, D. J., and Jefferson, A.: Measurements of new particle formation and ultrafine particle growth rates at a clean continental site, J. Geophys. Res., 102, 4375-4385, 1997. 